\title{
Talking About Transition \\ An Exploration of the Secondary to Tertiary Transition Process for Music Students in a New Zealand Context
}

\section{Lynne Wenden}

\author{
A thesis submitted to Massey University and \\ Victoria University of Wellington \\ in fulfilment of the requirements for the degree \\ Master of Music in Musicology
}

\author{
Te Kōkī
}

New Zealand School of Music 
(C) Copyright by

Lynne Wenden

All rights reserved

February 2015 


\section{TABLE OF CONTENTS}

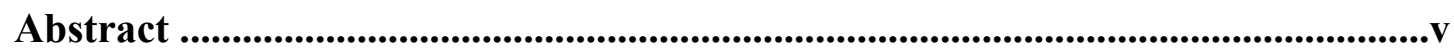

Acknowledgements .................................................................................................vi

List of Figures ..................................................................................................................................vii

Terminology, Acronyms \& Explanatory Notes....................................................viii

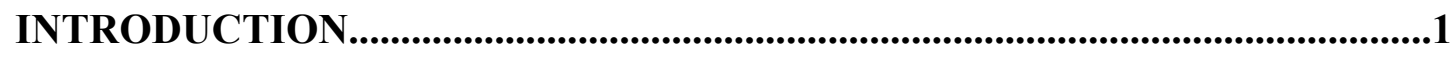

Language.................................................................2

Language and Positionality.................................................

Thesis Structure.............................................................4

\section{LITERATURE}

Epistemological Framework.....................................................................5

Research in the Field................................................................................99

Research Questions......................................................................................15

Thesis Statement................................................................................16

\section{METHODOLOGY}

Qualitative Research, Ethnographic Description, and Interpretivism.........17

Case Studies...........................................................18

\section{METHODS \& PROCESSES}

Contents Analysis........................................................21

Defining the Project Population ..............................................21 
CHAPTER ONE: A Language of Possibility - In Preparation

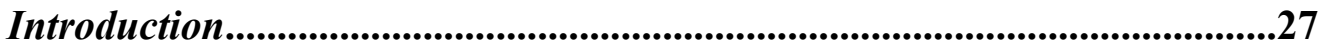

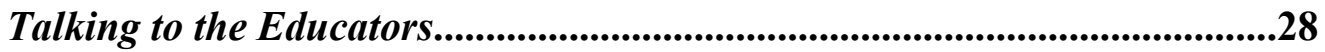

Case Study - Liz..................................................42

Student Disengagement and Identity Perceptions..........................47

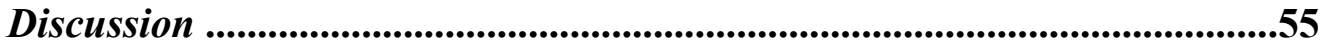

CHAPTER TWO: Troublesome Language - On the Threshold

Introduction .......................................................................................................57

Threshold Concepts..............................................................................................58

On the Threshold ..............................................................................................61

Threshold Concepts Widened.........................................................................64

Institutional Responsibilities...............................................67

Discussion...........................................................69

CHAPTER THREE: The Vernacular - Transitional Realities

Introduction............................................................................................................71

Case Study - Ata ..............................................................................................72

Discussion ......................................................................................................83

SUMMARY AND CONCLUSIONS.........................................87

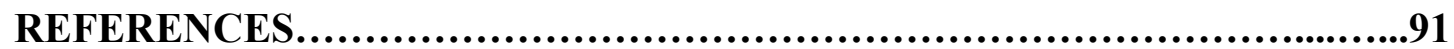

APENDICES:

Appendix I - Student Survey...........................................97

Appendix II - Follow-up Questionnaire...................................101

Appendix III - Secondary Student Survey..............................103

As Required for Ethics Approval:

Appendix IV - Participant Information Sheet............................105

Appendix V-Participant Consent Form .................................107

Appendix VI - Educator's Interview Framework..........................109 


\begin{abstract}
There are complex challenges facing music students majoring in performance in New Zealand as they transition from secondary to tertiary study. As a result of their pretertiary experiences, these students form identities and develop subjectivities that are often discordant with notions of a broadly conceived degree-level education. Through exploring transition using ethnographic and interpretive approaches, it is clear that significant numbers of performance students are not engaging with the more theoretical aspects of their music degrees and can in fact be actively resistant to acquiring knowledge in areas of the curriculum that they perceive as falling outside those necessary to become a performer. This research suggests that education systems in secondary schools in New Zealand contribute considerably to these student subjectivities as despite individual levels of knowledge that students bring to their tertiary studies, these systems result in significant homogenous subjectivities and approaches. More generally, secondary schools appear unable to consistently prepare music students for their tertiary music studies for reasons that include curricula that is: widely interpreted, compartmentalised, heavily weighted towards assessments, and, in terms of performance assessments, lacking in validity.

In 'talking about transition' within a New Zealand context, questions arise concerning pre-determined educational practices, which present unnecessary and prohibitive hurdles that can serve to culturally alienate our own students. For this reason and others, this research suggests these students will benefit from socio-culturally relevant pedagogical practice in addition to systems that provide accessible, manageable, and meaningful connections between secondary and tertiary levels of knowledge. Research findings also suggest that improved communication between education sectors and between institutions and students is key to empowering students with regard to their own learning.
\end{abstract}




\section{ACKNOWLEDGEMENTS}

Thank you to the many people who have contributed in various ways to this Master's project. Firstly, I extend my gratitude to all the music students and educators who agreed to be surveyed and interviewed, but whom I am unable to name for reasons of confidentiality. Thank you in particular to my case study contributors 'Liz' and 'Ata'.

A special thanks to my supervisor Dr Robert Legg and other staff at the New Zealand School of Music who have always challenged me to be the best I can be and for whose continued support I am immensely grateful. I also give warmest thanks to all my former music teachers in particular Rosemary Bromley whose professionalism and encouragement inspired this educational journey.

To my very talented post-graduate colleagues, Mel Cross, Kris Zuelicke, Hester Bell Jordan, Ailsa Lipscombe, Nell Thomas, Jonny Avery, and Cecilia Vincent - thank you for your help and for making the journey so enjoyable.

Finally, love and thanks to my family - For the wisdom and experience of an earlier generation, I thank Elinor, Nancy, Kelly, and my late father Bernard. For sharing the tertiary student experience with me and enriching the quality of this thesis I give my very fond thanks to my sons Matthew and Huw, and to Matthew's partner Olivia. Last, but not least, for the love and steadfast support that has made this Master's project possible, I thank my husband David. 


\section{LIST OF FIGURES}

Figure I: $\quad$ Age Range - Performance Students.......................24

Figure II: $\quad$ Performance Majors..................................24

Figure III: Performance Majors - Vocal and Instrumental Split..........25

Figure IV: $\quad$ Secondary School Education Systems........................25

Figure V: NCEA Achievement Criteria and Assessment Schedule.....36

Figure VI: $\quad$ Liz's 'Music as' Continuum ...........................44

Figure VII: The ‘Binary Flip Switch’ of Disengagement..........................47

Figure VIII: Performance Students’ Pre-tertiary Theory Qualifications....52 


\section{TERMINOLOGY, EXPLANATORY NOTES, and ACRONYMS}

\section{New Zealand School Decile Ratings}

Every school in New Zealand has a decile rating $(1-10)$ that corresponds to the economic wealth of the school's community. This system allows for additional funding from the government for low decile schools to help overcome barriers to learning facing students from low socio-economic households. The schools, students, and educators at the focus of this study are within the Wellington region; the decile ratings of the major secondary schools in this area do not drop below decile 8 . I do not detail the decile ratings of the schools outside Wellington from which various students in this study have had their secondary education with the exception of the student case study detailed in chapter 3 where the South Auckland college described has a decile rating of 3 .

\section{New Zealand Secondary School Years}

New Zealand secondary school (also known locally as college or high school) years begin at Year 9 (Y9) or $3^{\text {rd }}$ form and go to Year 13 (Y13) or $7^{\text {th }}$ form. Student ages typically range from 13-17.

\section{New Zealand Secondary School Qualifications: ${ }^{1}$}

\section{○ NCEA:}

The National Certificate of Educational Achievement is the principal tertiary qualification offered in New Zealand secondary schools. The qualification is completed over three levels and three years:

Level 1 (L1) NCEA begins Year $11\left(\right.$ Y11) or $5^{\text {th }}$ form.

Level 2 (L2) NCEA begins Year 12 (Y12) or $6^{\text {th }}$ form.

\footnotetext{
${ }^{1}$ This study is limited to discussing NCEA and IB qualifications. (Schools in NZ can offer Cambridge International AS and A2 exams however no students surveyed had studied Cambridge Music and no secondary schools in Wellington teach Cambridge Music).
} 
Level 3 (L3) NCEA begins Year 13 (Y13) or $7^{\text {th }}$ form. ${ }^{2}$

Students receive credits for 'standards' they sit, which can be assessed either internally by the school or externally by New Zealand Qualifications Authority (NZQA). Papers are either 'unit standards' that are limited to pass or fail or 'achievement standards' which can be endorsed with Achieved (A), Merit (M) or Excellence (E).

The same A, M, or E grading is applied to Levels 1 to 3 as a whole. For example, a student can pass Level 3 NCEA endorsed with an overall 'Excellence' by achieving a high standard (50+ Excellence credits) across a variety of subjects. ${ }^{3}$

N.B. In the pages that follow, the words Achieved, Merit, or Excellence when referring to NCEA grading or standards will be capitalised.

\section{NCEA Music Standards:}

There are multiple standards within Levels 1 to 3 NCEA music curricula. The specific standards I refer to are:

- Music Works

- Harmony

- Solo Performance
- Score reading

- Composition

- Group Performance

○ IB:

The International Baccalaureate diploma is a two-year qualification that certain schools (usually those privately funded) choose to run alongside NCEA. The IB course runs in the final two years of secondary school (Y12-13) and assessments are confined to the final year (Y13). Students who choose to do this qualification will typically have completed Level 1 NCEA in Y11.

\footnotetext{
2 It is possible for high achieving students to do 'accelerated' study. E.g. a student who is in year 11 may study L2 NCEA and year 12 students may study at L3 and so forth.

${ }^{3}$ For more detailed information about NCEA visit: http://www.nzqa.govt.nz/qualificationsstandards/qualifications/ncea/understanding-ncea/how-ncea-works/
} 
$\underline{\text { IB Music Standards: }}$

There are multiple components in the IB music curriculum. The specific standards I refer to are:

- Listening

- Solo Performance
- Composition

- Group Performance

\section{University Entrance (with NCEA or IB):}

To gain University Entrance a student in New Zealand must have three approved L3 NCEA subjects, ten literacy credits at L2 or above, and ten numeracy credits at L1 or above. Alternatively, a student can gain university entrance by completing and passing the IB diploma.

\section{First-Year University Requirements - BMus Classical Performance Students}

Based on first-year performance degree requirements at Institution A, the following details a typical workload for students in their first year of study: ${ }^{4}$

Four compulsory first year papers:

○ Performance: Study/tuition in chosen instrument/voice

○ Theory: Harmony and counterpoint, aural perception and keyboard studies

○ Theory: Tonal music procedures, conventional forms, melodic and rhythmic dictation

- Musicology: Understanding Music Through the Lens of the $20^{\text {th }}$ and $21^{\text {st }}$ Centuries

At least two optional first-year papers:

○ Musicology: e.g. Music history - Renaissance through to 21 st century

○ Performance: e.g. Accompanying, Large ensemble, or Dictation and language

\footnotetext{
${ }^{4}$ This information is taken at the time of writing and course content is subject to yearly reviews and changes.
} 


\section{First-Year University Requirements - BMus Jazz Students}

$\underline{\text { Six standard papers: }}$

- Jazz performance: Competency in chosen instrument/voice, basic piano skills

○ Jazz improvisation: Competency in improvisation skills and standard jazz language

○ Jazz ensemble: Ensemble playing techniques, repertoire knowledge

$\circ$ Musicology: Understanding Music Through the Lens of the $20^{\text {th }}$ and $21^{\text {st }}$ Centuries

○ Jazz History: Political and social contexts

○ Jazz Theory: Theoretical knowledge for composition, analysis, improvisation, and transposition

\section{International Music Qualification Boards:}

- ABRSM - Associated Board of the Royal Schools of Music

○ Trinity College - Trinity College London

These two institutions are the British examination boards preferred by private music teachers in New Zealand. They offer both practical and theory examinations.

\section{Additional Acronyms:}

NZQA New Zealand Qualifications Authority

NZSO New Zealand Symphony Orchestra

NZSSC New Zealand Secondary Schools Choir

SLS Student Learning Services

H.O.D. Head of Department

IRMT Institute of Registered Music Teachers 


\section{Talking About Transition \\ An Exploration of the Secondary to Tertiary Transition Process for Music Students in a New Zealand Context}

\section{INTRODUCTION}

If I had to reduce all of educational psychology to just one principle, I would say this: the most important single factor influencing learning is what the learner already knows. Ascertain this and teach him accordingly.

(Ausubel 1968)

In this often-quoted aphorism, the educational psychologist David Ausubel captures something intrinsic to the process of transition. He asks the educator to be concerned with a student's prior learning and to consider how this particular knowledge can be extended in ways that will allow him or her to progress successfully in a chosen field of study. The quotation contains two inherent assumptions that I consider central to the successful transition for music students from secondary to tertiary study. The first is that a student cannot be expected to advance effectively if his or her prior knowledge is not taken into account, and the second is that diversity across any particular educational cohort is assumed: Ausubel does not say 'students'.

Ascertaining any student's prior knowledge, however, is complicated by the circumstances in which this knowledge is acquired. Throughout this study I explore the importance of how and under what circumstances a student comes to 'know', thus exploring the nature of these learning environments and considering how they shape learning and subjectivities is crucial. In the process, I reveal tensions surrounding notions of individuality and collectiveness. For example, this research suggests that despite individual levels of knowledge that students bring to their tertiary studies, the secondary level educational systems under which they study in New Zealand can result in significant homogenous subjectivities and approaches. In addition, many music students in New Zealand majoring in performance face particular challenges at degree level due to their identity as emerging performers rather than as academic students. 
These particular tensions and anomalies are among the issues that I investigate in the pages that follow.

\section{Language}

A useful way in which to view the secondary to tertiary transition is through investigating language. Certain aspects of language, for example, institutional language, troublesome language, in addition to the empowering language used by students and educators are key to understanding the transitional issues facing music students in New Zealand. To foreground this idea, I introduce each chapter by examining certain aspects of language, for example, Chapter 2 details aspects of 'troublesome language' as a way of introducing the threshold concepts discussion that follows. More generally and by way of introduction to the politics and power of language, Henry Giroux provides this useful conceptual overview in an educational context:

One of the most important elements at work in the construction of experience and subjectivity in schools is language: language intersects with power just as particular linguistic forms structure and legitimate the ideologies of specific groups. Language is intimately related to power, and it constitutes the way that teachers and students define, mediate, and understand their relation to each other and the larger society. As [Mikhail] Bakhtin has pointed out, language is intimately related to the dynamics of authorship and voice. It is within and through language that individuals in particular historical contexts shape values into particular forms and practices. As part of the production of meaning, language represents a central force in the struggle for voice.

$(1986,59)$ 


\section{Language and Positionality}

It was almost forty years ago that my secondary school principal handed me a single sheet of paper - my final testimonial. Of the hundred or so words written there only a few stood out as if written in bold type. They said: 'Lynne is an average student of average ability'. Even then I could reason its inaccuracy, I had many skills, I was happy, gregarious, and successful in numerous ways - I had even represented my country. My principal was referring I imagine, because it was not specified, to my consistently average academic results, but for me it read as a broadly conceived and damning criticism. Despite all my successes then and in the years since, those few careless words continue to make their presence felt. Small setbacks take me back to a fundamental belief that I am, in reality, only 'average'. I am not alone in this; many students of my generation have experienced similar disempowering teaching. I include this anecdote, therefore, to provide just one example of the power of language to produce lasting subjectivities. It is a salutatory message to educators.

Equally powerful, however, is the way that language can reveal student subjectivities and the enquiry that forms the basis of this thesis is essentially driven by this concept. I come to this area of education research as a result of my interest and involvement in various music education contexts over the last twenty years. In my role as a registered music teacher, I have assisted a number of students through the performance and theory components of the NCEA qualification's three stages. As an adult tertiary music student, my relatively recent experience in undergraduate and postgraduate environments has given me direct experience of current music curricula at the tertiary level and indeed the associated challenges. Through relationships with other students both as a peer and as a tutor, I have gained a valuable perspective and particular insight into the types of issues facing students who have transitioned or are preparing to transition into music study at tertiary level. This experience leads me to some initial assumptions that this research is in part designed to test. The first is that New Zealand tertiary music institutions typically receive bodies of students whose diverse educational experiences result in baseline skills and knowledge that are far from standardised. Second, that the diversity of environments at secondary level implies variable modes of curriculum delivery. Third, I reason that tertiary entry qualifications tell only part of the story in terms of the students' prior learning experiences. For these reasons and those concerning the consequences that these experiences have for the 
student and institution alike, I believe that the transition between secondary and tertiary levels for music students is a necessary and important subject for research.

\section{Thesis Structure}

The main body of this thesis begins with a two-part literature review. The first section outlines the epistemological framework that informs my research approach. The second section details studies in the field that concern the student and includes discussions regarding students' academic backgrounds, motivation, and engagement. This section also includes specific research in the secondary and tertiary education sectors in addition to observations concerning students' personal beliefs about success and failure and their perceptions of the transitional process. A methodology section describing the qualitative, ethnographic, and interpretive approaches follows and the project parameters are detailed in the methods and processes section.

Chapters 1 and 3, when considered together, provide a 'before and after' framework of the secondary to tertiary transition process for music students majoring in performance. Both are underpinned by ethnographic and narrative approaches. Chapter 1 focuses on the pre-tertiary environment in New Zealand. I discuss issues and concerns related to New Zealand secondary school educational systems through the perspectives of secondary educators. The importance of student identity and engagement are also considered in this chapter through the first of two project case studies. The 'after' chapter, Chapter 3, introduces the second and more extensive case study. This case study serves two objectives: the first is to illuminate a lived reality of the secondary to tertiary transition through the experiences of a tertiary student about to complete her music degree. This case study also fulfils the second objective, which is to bring together issues and concerns that are discussed throughout this paper. Central to the thesis structure and central also to the transition process are discussions concerning threshold concepts. Chapter 2 takes a step back and focuses on the transition process through this theoretical lens. The crucial nature of students' experiences in their first or 'threshold year' is made explicit here. As detailed earlier, each of the three chapters begin with a description and explanation that relates to the overall language theme and each conclude with a discussion section summarising the main points. The thesis concludes with summaries and conclusions. 


\section{LITERATURE}

\section{Epistemological framework}

Music education's most important stakeholders: music students at all levels.

(Bradley 2012, 412)

In order to be explicit about the assumptions and theories that underpin this work (Burnard 2007, 143), this section of the literature review explores the body of literature that examines the broader philosophical arguments that shape the paradigms of enquiry. In addition to privileging the student, as the inclusion of the quote above suggests, I have identified three areas of critical social theory that hold particular relevance to music students' transition from secondary to tertiary study. These same issues inform, and often limit, on-going research initiatives and educational discourse. I begin with discussions concerning cultural capital and following this I consider issues of culture, class, ethnicity and gender. I conclude with theories concerning mythical norms, agency, and the student voice. Within these theoretical constructs and in the transitional process itself, I identify perspectives of both educators and students. Each have particular views of the secondary to tertiary transitional process and the tensions arising from these perspectives are theorised here and explored in more detail in the chapters that follow.

\section{Cultural Capital}

Pierre Bourdieu argues that the cultural capital invested in the mechanisms that drive institutional practice is difficult, if not impossible, to mediate by educational reform. He says, of the very close relationship between cultural practices and educational capital measured by qualifications, 'the more the competences measured are recognised by the school system, and the more "academic" the techniques used to measure them, the stronger is the relation between performance and educational qualification' (1984, 13). Musical complexity, for example, is one such quality that legitimises classical music as particularly valuable ideologically. Institutionalisation of 
music study helps to perpetuate these ideologies; moreover, music education participates in the construction and perpetuation of ideologies about musical value. Highlighting the power and extent of education as cultural capital, Lucy Green states explicitly that it is music education that has 'been a central mechanism in the establishment and maintenance of the classical canon' $(2012,209)$.

Bourdieu also discusses what implications reified traditional teaching methods mean for the student. He explains that 'if students are characterised as a unitary body and their diversity and interests are set aside, predetermined and hierarchically arranged knowledge becomes the disseminated cultural currency and, ultimately, the structuring principle around which the school curriculum is organized and legitimised' $(1984,13)$. Such a predetermined and hierarchically arranged curriculum has equal implications for educators. Estelle Jorgensen, for example, maintains that Western educators' preoccupation with musical instruction methods over the last two hundred years ignores the variety of ways in which people understand music. She comments that 'the fact that instructional methods have been worked out to a high degree of sophistication and defended as if they were dogma is oppressive to teachers' $(1997,91)$. Jorgensen believes, rather, that teachers are more empowered if they are able to work in creative and imaginative ways in order to meet students' needs $(1997,91)$.

\section{Issues of Culture, Class, Ethnicity, and Gender}

The basis of many educational ideologies concerning student needs and teaching and learning practices are issues surrounding culture, class, ethnicity, and gender. In this, Giroux considers the overarching concepts of power relationships and agency when he comments that educators, purporting either radical or conservative ideologies, can be indifferent to democratic processes and the ways in which these processes are managed and negotiated by students in educational environments. These educators generally fail, he says, 'to engage the politics of student voice and representation - the forms of narrative and dialogue around which students make sense of their lives and schools'. He asserts that such indifference is 'at odds with the notion of human agency' and further, they represent 'a serious theoretical and political failing on the part of educators' $(1986,48)$. To ameliorate such failings, Giroux suggests that educators need to confirm the experiences of students who are 'silenced by the dominant culture of 
schooling - which generally represent and legitimise the privileged voices of the white middle and upper classes'. Ultimately, he asks educators to be aware of how power, dependence, and social inequality enable and limit students in terms of class, race, and gender (1986, 64-5). Similarly, Paulo Freire addresses asymmetries of power relationships when he warns educators against disregarding cultural and creative knowledge in attempts to fill 'empty vessels' with deposited knowledge that is, at best, expressions of a dominant ideology $(1985,30)$.

In this context and more recently, specific learning and teaching strategies have been implemented to provide more diverse opportunities for students. There is evidence that certain strategies, for example those involving student choice, emphasis on aural learning methods, group work, and more self-directed learning, lead to increased motivation and more diverse opportunities for students from different classes and cultures. Students with such opportunities are more likely to succeed at all educational levels (Green 2012, 212). Deborah Bradley argues that:

Education is obliged not only to transmit officially sanctioned forms of knowledge but also work with the knowledge students bring to the classroom from their lives outside school. This is crucial if pedagogy is to be culturally relevant, and if students are to make meaningful, important, and durable connections between and among school knowledge, family life, community relationships, cultural practices and personal interests $(2012,414-15)$.

Green maintains that the traditions of Western classical music tend to reinforce social class and gender differences; however, she cautions that the introduction of multicultural or world music into the curriculum in order to mitigate ethnic barriers can be complex. In this, she gives examples of the reluctance by ethnic minority students to reveal their listening preferences, for example Hindi film music. She explains that students can be 'shamed and secretive' due principally to peer pressure and thus these complexities mean that multiculturalism in music education can 'unwittingly affirm ethnic power and status differentials rather than breaking them down' $(2012,214)$. 


\section{Mythical Norms, Agency and the Student Voice}

Paradoxically, the only way to think of students collectively might be through acknowledging their diversity. Elizabeth Ellsworth, for example, argues that students are not, as some educationalists assume of a student body, some mythical norm typically assumed, among other attributes, to be young, white, heterosexual, Christian, and English-speaking (1989, 323). In essence, these unique individuals with their diverse needs and expectations problematise the very term 'student voice' $(1989,312)$. Giroux, who maintains that it is important to acknowledge students' subjectivities, articulates the importance of this. He says students have diverse readings, mediations and behaviours that affect their responses in particular educational contexts. He stresses that educators need to be attentive to the 'histories, dreams, and experiences' that students bring to the classroom and argues further that we should 'interrogate the ways in which people create stories, memories, and narratives that posit a sense of determination and agency' $(1986,64)$.

If institutions are attentive to the diversity of experiences that students bring to their tertiary study then it is difficult to justify describing them as 'ill-prepared' as Robert Gauldin and Mary Wennerstrom, for example, have suggested when referring to subjects such as harmony and counterpoint. They charge that: 'Many entering college students are ill prepared not only in this standard body of music, but also in areas such as basic language ability and knowledge of general history and culture' $(1989,68)$. If students are failing to meet set standards and if the institutional focus is on reorganising rather than revisiting curriculum content then, as Giroux comments, "not only do the students bear the sole responsibility for school [or course] failure, but also there is little room for questioning the ways in which administrators and teachers actually create and sustain the problems they attribute to students' $(1986,59)$.

These theories and observations regarding issues of cultural capital, power relationships and agency, the diversity of student needs, and the organisation and legitimisation of curriculum design are at the heart of this project's parameters and approach. Underlying this and fundamental to exploring the narratives of students and educators is an urgent need to understand how educators and students interpret their teaching and learning environments. It is something that I reiterate and explore throughout taking my lead from Ellsworth who proposes cultivating a 'third ear' that 
'listens not for what a student knows (discrete packages of knowledge) but for the terms that shape a student's knowing ...' $(1997,71)$.

\section{Research in the Field}

In this section of the literature review I principally address transitional research that focuses on the student. Research concerning the student includes discussions of students' diversity of backgrounds, their identities and attitudes, their confidence and status, and the crucial nature of their prior knowledge and experiences. The institutional research detailed here is also student-centric; it includes matters relating to transition, organisational priorities, relevance of prescribed courses, and awareness of the diversity of student backgrounds. Jan Parker, for example, believes in regard to successful transitions that it is the universities that have the responsibility to bridge gaps; the responsibility, she insists, does not lie with the individual. The focus, therefore, shifts to examining curricula, assessment practices, and teaching methodologies in order to consider the extent to which they impede or facilitate student access $(2003,63)$. Access to higher education, she argues, is 'an issue of institutional and systematic transformation rather than individual remediation' (ibid.).

The transition from secondary to tertiary study for music students has not been the focus of specific research undertaken in New Zealand, however, research centered on the secondary-school sector is particularly relevant in terms of curriculum design and student preparation. With regard to knowledge acquisition at the secondary-school level Graham McPhail, lecturer in Critical Studies in Education at Auckland University, has written extensively about on-going music curriculum restructuring that has led to significant diversification in terms of knowledge structures, content, and specification (McPhail 2012a, 2012b, 2013). Using Bernstein's (2000) theories of knowledge differentiation (vertical and horizontal discourse), he maintains that music as a subject has specific and unique requirements with regard to knowledge acquisition that requires diverse approaches that include both hierarchical (vertical) structures in addition to conceptual awareness of stylistic segmented conventions (horizontal) (McPhail, 2012b). Despite the positive benefits of variety in curriculum content and flexibility of study choices that are designed to meet the needs of the students, McPhail's concerns lie with a lack of awareness in curriculum design, which presumes 
such approaches to be dichotomous. As a result of a growing emphasis on flexible and horizontal approaches, there is considerable 'under-specification of knowledge content and progression' that ultimately hinders student learning (2012b). Essentially, McPhail believes that The New Zealand Curriculum ${ }^{5}$ 'appears to support knowers over knowledge' and the regionalised flexible framework results in allowing 'teachers to avoid assessing, and presumably teaching, areas that their students may find less relevant or more difficult' (2012b). 'Universities', he claims, 'have no choice but to respond to curriculum changes as students with a lack of traditional knowledge but new and varied skills undertake tertiary study' (2012b).

Research beyond New Zealand that focuses specifically on music student transition makes up the larger proportion of the relevant literature and like Parker's research detailed above, the following are examples of work that has been undertaken in Australia and the United Kingdom. As members of the former British Commonwealth, New Zealand and Australia have close links to Britain and the British-derived education systems. In addition to recognising work undertaken in these countries, I have considered educational research that looks at the secondary to tertiary transitional process more generally as the many transitional issues raised in the chapters that follow are inter-disciplinary.

A commissioned report by Peter Renshaw for the Queensland Conservatorium is an example of such institutional research. The report, designed to investigate their strategic future, questions existing practices and re-positions notions of agency toward the student and his or her present and future needs. Renshaw identifies key issues and larger pedagogical initiatives that need to be negotiated within the constraints of organisational concerns and priorities. Among the questions he asks of any organisation focused on change and preparing for the future are: 'How far is the training sector reappraising its patterns of organization and the scope and diversity of its courses in order to respond to the wide range of musical genres and artistic practices within the music industry? Does the content of courses, and the environment in which

\footnotetext{
5 The National Curriculum is composed of The New Zealand Curriculum and Te Marautanga o Aotearoa, which set the direction for student learning and provide guidance for schools as they design and review their curriculum. For further information visit: http://nzcurriculum.tki.org.nz/The-NewZealand-Curriculum
} 
students learn produce the kind of musicians who will be able to thrive and adapt within a multi-stranded industry? Does the scope and diversity of courses offered respond to the wide range of musical genres and artistic practice within the music industry'? ${ }^{6}$ Renshaw comments that institutions like the Queensland Conservatorium must realign their priorities if staff and students are going to meet the needs of a changing world. In this, and in the context of the present study, I consider the next observation he makes central. 'Institutions must', he asserts, 'encourage innovatory approaches and position research and continuing professional development as the artistic and educational motor which underpins the work of the institution' (2002, 1316). The insistence on these kind of innovatory approaches is taking hold if not always in practice at least in discourse that prioritises the current needs of music students and the futures of music student graduates. There is, for example, extensive literature that calls for questioning the veracity, relevance, and practicality of simply transmitting values from the past (Bradley 2012, Carey 2004, Giroux 1986, Jorgensen 1997, Parker, 2003, Tregear 2014).

Of the quantitative studies weighted toward accumulating and interpreting statistical data, one such example examines undergraduate success rates by investigating students' background variables. In this research, Carole Harrison attempts to predict theory, aural, and keyboard component grades based on measures of academic ability and formally tested musical aptitude. For reasons that include the contested notions of both 'ability' and 'aptitude', and despite complex quantitative analysis, her conclusions are variable and perhaps predictable. Harrison concedes, for example, that variations in grades go unexplained; effects of musical experience are 'unclear' as are grades related to what she refers to as the 'principal instrument factor' $(1990,184)$. Other related studies aim to develop an understanding of students' own beliefs about success and failure (Asmus 1986, Spencer 1993). While empirical studies of this sort provide valuable statistical starting points and offer general observations that contribute to a wider knowledge base in the field, they typically remain disconnected to wider pedagogical concerns and initiatives. If studies such as these presume of a student body a mythical norm, their findings, if any, are rarely transferable and as such are of limited value to the wider educational community. As I argue in more detail later, quantitative

\footnotetext{
${ }^{6}$ These issues were previously raised by Rick Rogers in 'Creating a Land with Music' 2002.
} 
approaches in general may tell us if something is, or is not, working - they do not, however, reveal the complexities of why that is so.

By way of contrast and with reference to future employment trajectories, the collaborative mixed-method study by Rosie Burt et al. acknowledges student diversity as it relates to prior learning engagement and current learning approaches. Through semi-structured interviews, these authors attempt to understand students' own ideas about their learning and about their future aspirations (2007). Similarly, Karen Burland and Stephanie Pitts look at students' perceptions of the transition process. They found that, in addition to difficulties negotiating responsibility for timetabling, tutorials, lectures, workshops, lessons, and practice, many music students feel a loss of the star status that they enjoyed at secondary school. The adjustment from being 'one of the best musicians at school to being one of similarly skilled people presents particular challenges for many music students' (2007, 303). Burland and Pitts make three observations that relate specifically to the present topic and that I address in my approach. Firstly, they find that lecturers typically have no direct knowledge of styles and content of secondary level curriculum and in general have out-dated assumptions about students' prior learning. Secondly, they stress that students' attitudes to learning are inevitably shaped both academically and socially by their school experiences and their expectations of university life. Lastly, they note that consistency of academic and musical skills cannot be assumed across a given cohort and argue that there is a responsibility for lecturers, with support from their institutions, to address this (2007, 290-295). Anthony Cook and Janet Lecky support these views and contend that in order to ease the student transition, it is essential that 'university staff have an informed view of the diversity in the backgrounds, needs and aspirations of the students they teach' (1999, 158). Additionally, they comment that there needs to be 'greater awareness among academic staff of the qualities and skills which new students bring to their university studies as well as explicit statements of those qualities and skills which are desirable to assist new university students to study effectively' $(1999,170)$.

Burland and Pitts' data indicates strong transferability across the domains of performance and academic confidence - that is, for students, confidence in one area of study transfers to confidence in others. My own research does not reveal the same 'strong transferability' for reasons that I discuss further in Chapter 1. In this regard, I respond to their challenge that asks for further enquiry into the extent to which learning 
attitudes from school shape students' academic development (2007, 299). Expanding on her collaborative work, Pitts (2013) privileges the student perspective using interviews and a qualitative approach in her study of transition. She cites course difficulties and living away from home as the principal reasons for students leaving university and identifies minimal awareness of course content in addition to dissatisfaction with teachers/lecturers as the main difficulties for students. Although a reasonable starting point, Pitts does not adequately document the reasons why course difficulties or minimal awareness of course content are significant in students' withdrawals.

Performance students' musical identities, as I discuss further in Chapter 1, are significant in determining how they will approach their tertiary music studies. It is something that others consider in their research albeit in slightly altered contexts. Pitts, for example, finds that students' identities as musicians are challenged at tertiary level and that they are often 'critical of their entitlement to be called musicians' $(2013,217)$. Henry Kingsbury makes a related point about confidence and identity. He notes that, 'students' talent, ${ }^{7}$ a mark of their remarkable individuality, suddenly becomes a mark of similarity with all the other performance students $(1988,4-5)$.

Specific studies that pertain to institutional concerns and that motivate further research in the transitional field include a study by Russell Gavin who addresses issues of transition and experiences amongst music education students at tertiary level. Although pre-tertiary experience is noted and included in his questions and surveys, Gavin's focus is on student persistence or withdrawal factors. His findings suggest, 'frustratingly' by his own admission, that some traits thought to be consistent among persisting music students might also be consistent among withdrawn students. In this respect, he suggests that further research examining pre-tertiary traits among the population of withdrawn students is needed as well as developing a more detailed understanding of the experiences students encounter. In the context of the previous observations regarding relevancy and agency by Giroux and Peter Tregear, it is most significant that Gavin found that all withdrawing students were still actively involved in music making and foresaw that music was going to be a major part of their on-going lives (Gavin 2012).

\footnotetext{
${ }^{7}$ The notion of 'talent' is yet another debated construct. In this context Kingsbury uses the word to mean 'ability'.
} 
Alternative research approaches that address the student specifically include the interest in student-based teaching and learning strategies. Such studies have been an example of the recognition that more traditional educational models are no longer satisfying the diverse needs of students. Student-based programme initiatives are well documented and are approached from a variety of perspectives. Researchers are, for example, rejecting the notion that teachers are the primary source of knowledge and are proposing that pedagogical approaches must recognise the abilities of students to direct their own learning (Lebler 2008). There is also awareness that students do not share the same 'musical habitus' (Regelski 2004) and that they have different objectives behind their engagement with any subject. As a result, these differences in habitus impact on how any subject is digested across the student group (2004).

As a musical habitus is inherently part of a larger cultural habitus, it is understandable that attentiveness to accommodating cultural diversity is more evident in today's classrooms. This cultural awareness is driving more recent initiatives in music education. This research tells us that knowledge needs to be culturally relevant and institutions must work with the knowledge that students bring to the classroom if they are to make meaningful connections between 'school knowledge' and their communities, cultural practices and personal interests (Bradley 2012, De Graaf and Wolbers 2003, Green 2005, Rideout 2005, Small 1996). These ideas are supported more generally by others who, in discussion concerning curriculum relevancy, argue that students are often faced with fragmented and segregated courses that seem to have little connection with or relevance to each other or to the students' own lives. If students' interests, ideas, and abilities are considered in pedagogical practice, the learning process becomes much more meaningful and the subject areas they face are no longer just a series of irrelevant hurdles to be jumped in order to satisfy some externally imposed requirement (Jorgensen 1997, McCoy 2011, Parker 2003, Servias 2011).

In the New Zealand context, cultural, statistical, and evaluative studies motivated by poor retention and pass rates of Maori students at tertiary level include those who consider the moderating effects of well-being, cultural identity (knowledge of whakapapa, ${ }^{8}$ tikanga, ${ }^{9}$ te reo Maori, ${ }^{10}$ whenua, ${ }^{11}$ and whanaungatanga), ${ }^{12}$ and

\footnotetext{
${ }^{8}$ Whakapapa - genealogy, which create a foundation of meaning.
} 
perceptions of academic control (control students feel they have over their academic outcomes) as empowering resources in relation to stress and academic motivation in the university environment (Watene 2006, Gavala \& Flett 2005). In terms of wellbeing, persistence, and success, these researchers note the importance in providing culturally congruent environments - often informal and interactive - for Maori students. Gavala and Flett also accept that further research is required regarding 'appropriate measurement tools to identify specific components of a diverse Maori cultural reality' (2005, 57, my emphasis). Examining such cultural diversity - mindful of aforementioned mythical norms associated with any student group - is arguably best achieved through ethnographic approaches as I argue through the narrative methodology I employ in Chapter 3.

\section{Research Questions}

The many topics addressed in the literature review inform my research approach to a greater or lesser extent. I consider it problematic, for example, if traditional or conservative ideologies are perpetuated in music education if, as a result, students then take full responsibility for course failure. It is equally problematic if social and cultural barriers are reinforced through pedagogical practice or if students are identified as a unitary body and their diverse interests are set aside. The research questions arising from the literature and that I address in a specifically New Zealand context are: Do secondary and tertiary educators have sufficient knowledge of each other's educational environments? Do they assume levels of knowledge across the student cohort? Are students' diverse needs being accommodated? Are students getting access to important, powerful and portable knowledge? Lastly, to what extent are students' pre-tertiary educational experiences, ideological constructs, and expectations of their tertiary study affecting their approaches and attitudes to learning? In making efforts to understand perceptions and 'learning attitudes', and by focusing specifically on the New Zealand context, the intention here is to broaden our understanding of both the educational and

\footnotetext{
9 Tikanga - customary system of values and traditions.

${ }^{10}$ Te reo Maori - Maori language

${ }^{11}$ Whenua - literally means the land or alternatively placenta, however, it refers to the deep associations with place and nurturing concepts through one's birth and those of one's ancestors.

${ }^{12}$ Whanaungatanga - relationship, connection, or in this context - the concept of inclusive learning.
} 
socio-cultural influences that are brought to bear on students' future learning at the tertiary level.

\section{Thesis Statement}

This thesis explores the transition between secondary and tertiary study for music students majoring in performance in New Zealand. Whether a student transitions successfully or not has considerable repercussions for the student and the institution alike. This research suggests that significant numbers of performance students do not engage with the more theoretical aspects of their tertiary music degrees for reasons that are directly connected to their pre-tertiary educational experiences. Moreover, I suggest that these students can be actively resistant to acquiring knowledge in areas of the tertiary music curriculum that they perceive as falling outside those necessary for becoming a performer. In this, and with regard to these pre-tertiary educational and socio-cultural experiences, I find that understanding how and under what circumstances a student comes to know is crucial.

In a specifically New Zealand context, I argue that variable delivery of music education across secondary schools contributes significantly to the diversity of students' baseline skills and knowledge they arrive with at university. Despite this, the same pretertiary environments are contributing to considerable homogenous and often counterproductive subjectivities. For performance students, identity formations are significant. In this, whether a student identifies himself or herself as a musician or as an academic student is particularly relevant with regard to his or her engagement with tertiary music studies. Students have their own understandings of their musical identities, musical education, and musical development. By exploring the language they use to describe these understandings, I believe we discover an opportunity to comprehend the ways in which they will or will not approach new learning situations at university. 


\section{METHODOLOGY}

\section{Qualitative Research, Ethnographic Description, and Interpretivism}

In being attentive to students' experiences and conscious of the processes surrounding knowledge acquisition, the methodologies that inform my approach are essentially interpretivism and ethnography. Interpretivism is characterised by a concern for the individual; it places emphasis on a social reality and on human agency and with the understanding that people interpret reality in different ways. Realities, in this sense, are multiple, constructed and context dependent and to work within the interpretive paradigm is to make efforts to get inside the person and understand them from within (Cohen, Manion, and Morrison 2011, 17, 219). Similarly, interpretivism assumes anthropology is a semiotic endeavour, thus 'interpretive practice traces the manner in which meaning is ascribed' (Geertz 1973, 20). Ethnographic description is interpretive of the 'flow of discourse' and the interpreting involved consists in trying to 'rescue the "said" of such discourse from its perishing occasions and fix it in pursuable terms' $(1973,20)$.

As stated earlier, this project stems from interests and concerns in a community that I have involvement in and direct knowledge of. As Deborah Wong notes, ethnographic work within one's own community allows for a certain honesty and authenticity. Consequently, employing ethnographic strategies within an interpretive framework works toward an understanding of particularities in a specific environment. The ethnographic process then, in this context, endeavours to make broader observations suggested by those particularities $(2004,8)$. We are in a better position to understand student perspectives through the use of such approaches and this is critical if educationalists are to develop practices that are both relevant and inclusive and if they wish to have an informed view of the diversity in the backgrounds, needs and aspirations of the students they teach (Cook and Leckey 1999, 158).

The overarching qualitative approach of this project, as suggested previously, is motivated by a belief that empirical and quantitatively weighted research may tell us something about what is happening in any situation, it will not, however, tell us why. 
Edward Asmus, for example, wrote that he believed one day a 'reliable and valid measurement device' would be found that would further research into the motivation factor in students' musical achievement. In a study that essentially deals with students' own beliefs about their successes and failures, he sought a comprehensive factor analysis that he reasoned could be 'validated empirically' $(1986,275)$. In this sense he was attempting to objectify socially constructed realities; by doing so his empirical methodology was perhaps misdirected. By contrast, the approach here relies upon 'thick description' (Geertz, 1973) where the conceptual structures and meanings of student perspectives are contrasted against the 'thin description' of uninterpreted factual accounts. ${ }^{13}$ On this, Clifford Geertz is worth quoting at length:

If anthropological interpretation is constructing a reading of what happens, then to divorce it from what, in this time or that place, specific people say, what they do, what is done to them, from the whole vast business of the world - is to divorce it from its applications and render it vacant.

As others have argued, "narratives are a foil to the supremacy of coding and coding derived analysis' (Cohen et al. 2011, 552). This interpretive and ethnographic approach ensures that qualitative accounts refine data collected and as such are perhaps subject to interpretive construction but not invention. Additionally, collected information avoids the naivety that both empirical and statistical analysis has in seeking to guarantee the quality of the work (Morrison 2002).

\section{Case Studies}

The inclusion of case studies in this thesis augments my commitment to the notion of privileging the expression of student voices. A case study methodology allows the students to speak for themselves with descriptive detail that enables the reader to reach an understanding that is more meaningful and more coherent than is possible through theory or principle alone. As a prototypical instance of mixed methods research, case studies observe real effects in real contexts - they explain, describe, illustrate, and enlighten (Cohen et al. 2011, 289-91). Music education, as an academic discipline,

\footnotetext{
13 'Thick' and 'thin' description is terminology borrowed by Geertz from Gilbert Ryle.
} 
straddles the boundaries of thought and action and work within this field needs to reflect the demands of balancing theoretical principles with practical realities. The use of case studies, in this context, is intended to fuse the theory and the practice to enable a clearer understanding of issues that are presented with rich description and detail. By privileging student perspectives, this thesis argues that understanding the diverse musical and schooling experiences with which students arrive at university leads to more meaningful learning and teaching practices. In this, Paul Black and Dylan Wiliam ask simply: 'Do I know enough about my students to be able to help them?' $(1998,10)$.

As outlined in the introduction, the two case studies used in Chapters 1 and 3 respectively, when viewed together, can be seen to form a framework of the secondary to tertiary transitional process. The first of these studies is 'representative' (Cohen et al. 2011, 291) and details high school perceptions and tertiary study expectations from 'Liz' a student intending to further her music study at university. The second study is more 'revelatory' (ibid.) and focuses on 'Ata' a student in the final throes of completing her courses in order to graduate with a Bachelor of Music majoring in vocal performance. In both cases I endeavour to leave the students' narrative relatively free from interspersed commentary and reserve the majority of this for the concluding sections. 


\section{METHODS \& PROCESSES}

\section{Content Analysis}

Content analysis 'defines the process of summarising and reporting written data - the main contents and data and their messages' (Cohen et al. 2011, 563). This project methodology requires the study and interpretation of material or texts gathered principally through surveys and interviews. In this respect, content analysis is the process by which one analyses, interrogates, and summarises these texts through the use of pre-existing categories and emergent themes in order to generate or test a theory (2011, 564). It is particularly useful in the ethnographic context as its focus is on language and linguistic features - placing meaning in context and thus breaking down linguistically constituted facts $(2011,563-64)$.

\section{Defining the Project Population}

The research population refers not only to the people involved in this project, but to the 'domains of analysis' $(2011,564)$ - that is the text, surveys, interviews converstations, from which thematic analysis is derived.

The principal participants in this research project are:

- Fifty-eight classical and jazz tertiary performance students at a large, comprehensive music school based at one of New Zealand's more researchintensive universities (Institution A). ${ }^{14}$ All students have attended secondary schools in New Zealand. ${ }^{15}$

Other participants include:

- Performance students in Years 12 and 13 at Wellington secondary schools who intend to study music at a university.

\footnotetext{
${ }^{14}$ Discussions regarding performance degrees at tertiary institutions are limited to universities as opposed to performance music courses at Institutes of Technology and Polytechnics in New Zealand. The latter are another context which might reveal different findings than those described in this study.

${ }^{15}$ There is room for research into aspects of transition for students who have had their secondary preparation outside New Zealand. These students are not, however, the focus of this project.
} 
- Music educators based in Wellington

- Secondary School

- University (limited to specific performance tutors)

- IRMT

\section{Principal Survey Group - Tertiary Music Students}

- Initial Survey ${ }^{16}$ - Following a verbal explanation of my Master's project, an initial survey was administered to music students enrolled at Institution A. By targeting students in a 100-level compulsory course the intention was to have the majority of respondents in their first year of tertiary study. Other classes surveyed, in this purposive sample, were orchestral rehearsals and a variety of instrumental and vocal performance workshops; these included students at all levels. There were three layers of enquiry that the survey interrogated:

- Basic details - age, location of secondary schooling, music major (e.g. voice, cello, music studies), and current year of study.

- Pre-tertiary experiences - performance and theory qualifications, extent of musical engagement and activities, details of music tuition both private and through the various educational systems.

- Transitional experiences - perceptions of academic and musical preparation for university study and experiences and challenges at university. This level allowed for personal and interpretive responses, for example, reasons given for choosing to study music at university.

- Follow-up Student Questionnaire ${ }^{17}$ - Students were asked in the initial survey to provide contact details if they were willing to participate further in the study. Responses (seventy-three) to the original survey were collated and various observations and statistics gathered. Using the survey to screen potential participants (Cohen et al. 2011, 22), students who did not have their secondary schooling in New Zealand were eliminated. It was also at this point I considered the response from the performance students to be sufficient material

\footnotetext{
${ }^{16}$ See appendix I, pg. 97 (This initial survey was originally designed for all music majors.)

${ }^{17}$ See appendix II pg. 101.
} 
for a detailed focus. Thus, the follow-up questionnaire was distributed by email to these fifty-eight performance students. This questionnaire clarified questions that pertained to these students' original survey answers and included additional questions that elicited finer detail regarding their perceptions of the secondary to tertiary transition process.

○ Semi-Structured Interviews - In addition to the survey and questionnaire, an important element of information gathering was to conduct semi-structured interviews where ideas from the questionnaire, for example, were discussed at greater length. Interview lengths ranged on average between forty-five and ninety minutes and were transcribed verbatim. The interview participants were chosen by their willingness to participate further in the research process (see surveys above) and by reviewing survey and questionnaire answers that were particularly detailed with regard to the secondary to tertiary transition process. The editing of these transcripts in this document is limited to thematic arrangement with small word changes where it is necessary to maintain anonymity. Where required, square brackets are used to clarify or qualify.

The following graphs and statistics provide an aid to understanding the boundaries of the study and the participants involved. This mixed method approach increases the accuracy of data and provides a more complete picture of phenomenon thus ameliorating potential weaknesses of a single approach (Cohen et al. 2011, 22). 
Tertiary Performance Student Survey Statistics

Figure I: Age Range - Performance Students

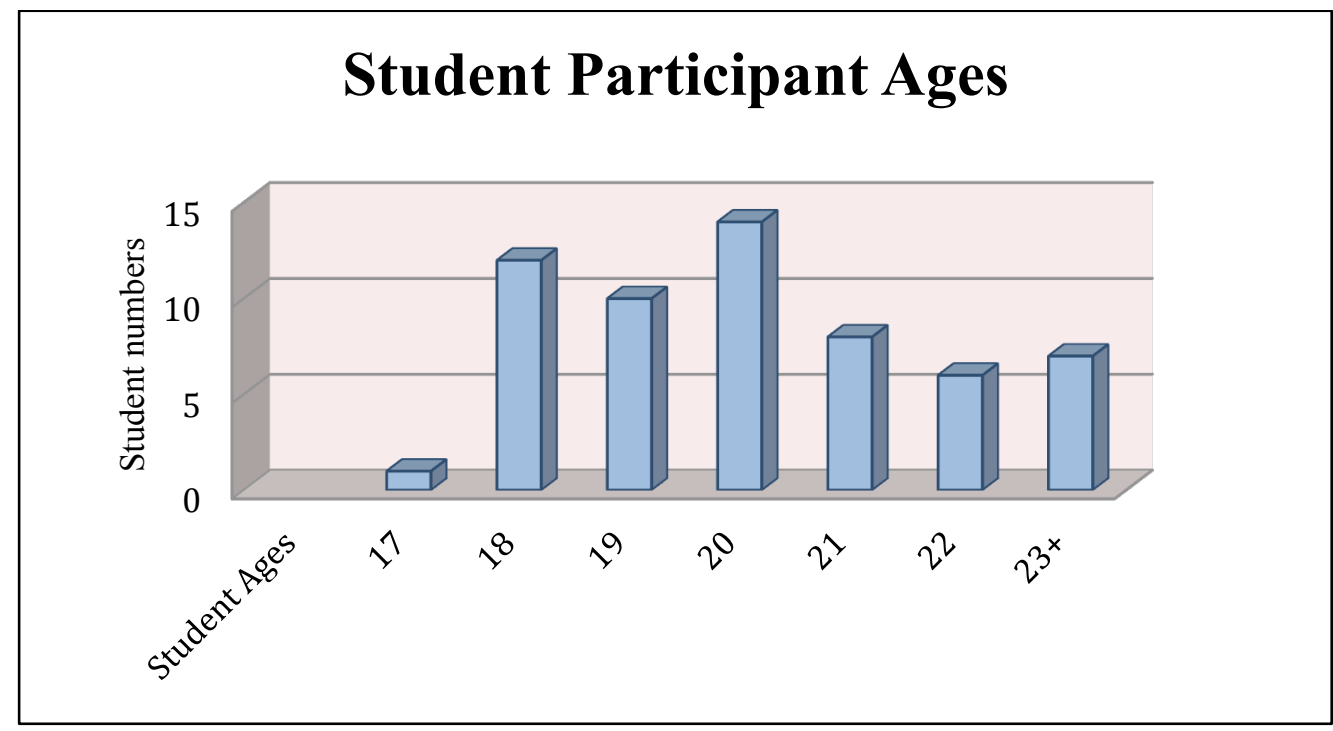

Figure II: Classical and Jazz Performance Majors

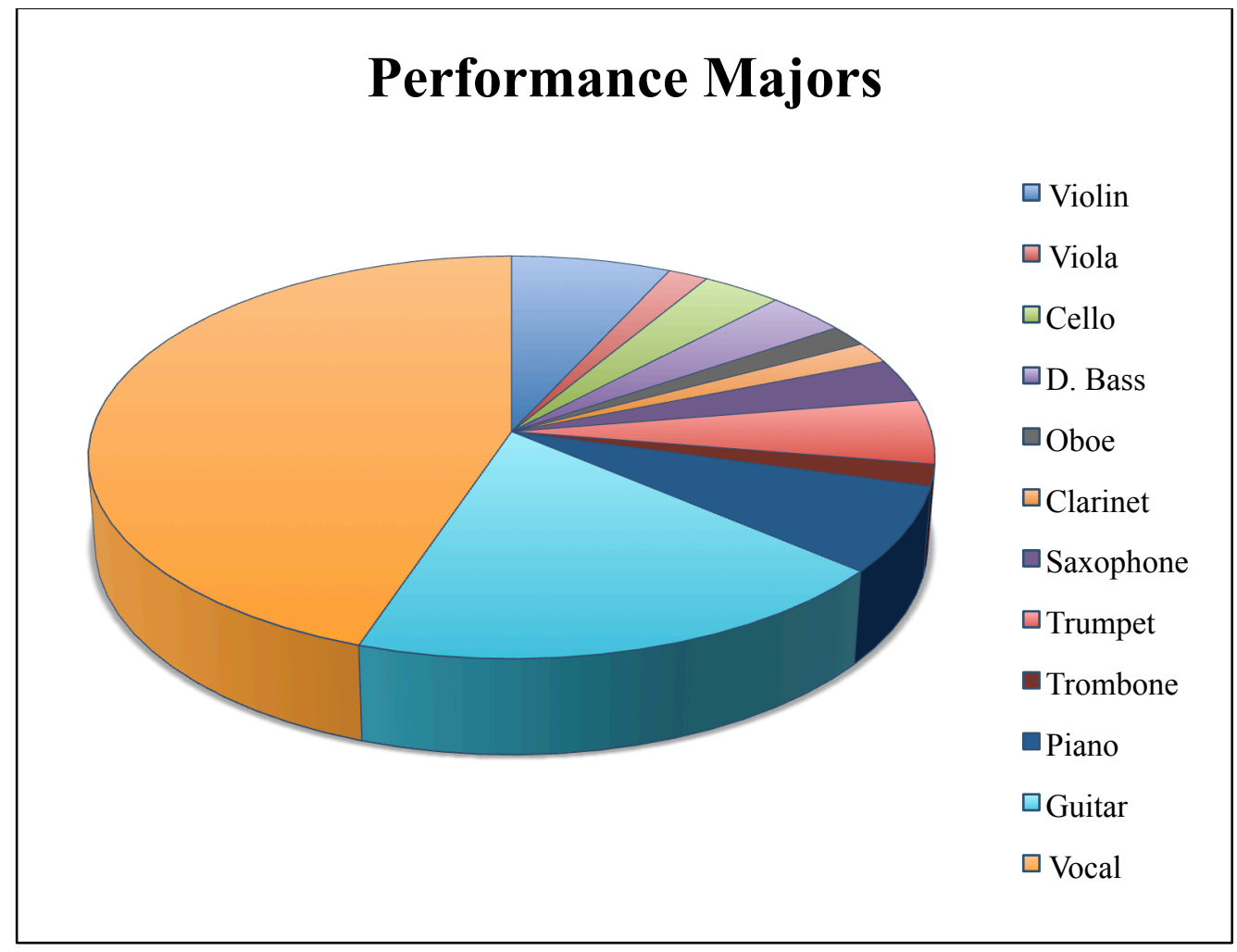

In addition to the respondents from the 100-level compulsory course, the spread of vocal and instrumental performers/respondents was largely determined by the accessibility and willingness of the students, lecturers, and tutors concerned. 
Figure III: Performance Majors - Vocal and Instrumental Split

\section{Vocal \& Instrumental Split}

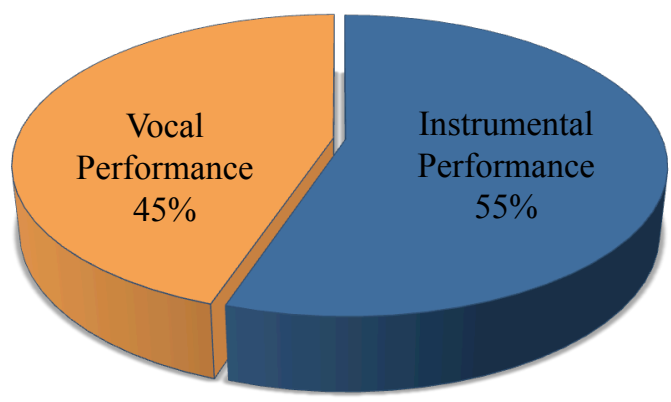

Figure III shows that despite some performance majors being more highly represented than others, there is nevertheless a relatively equal distribution of survey respondents between vocal and instrumental performers.

Figure IV: Performance Students' Secondary School Education Systems

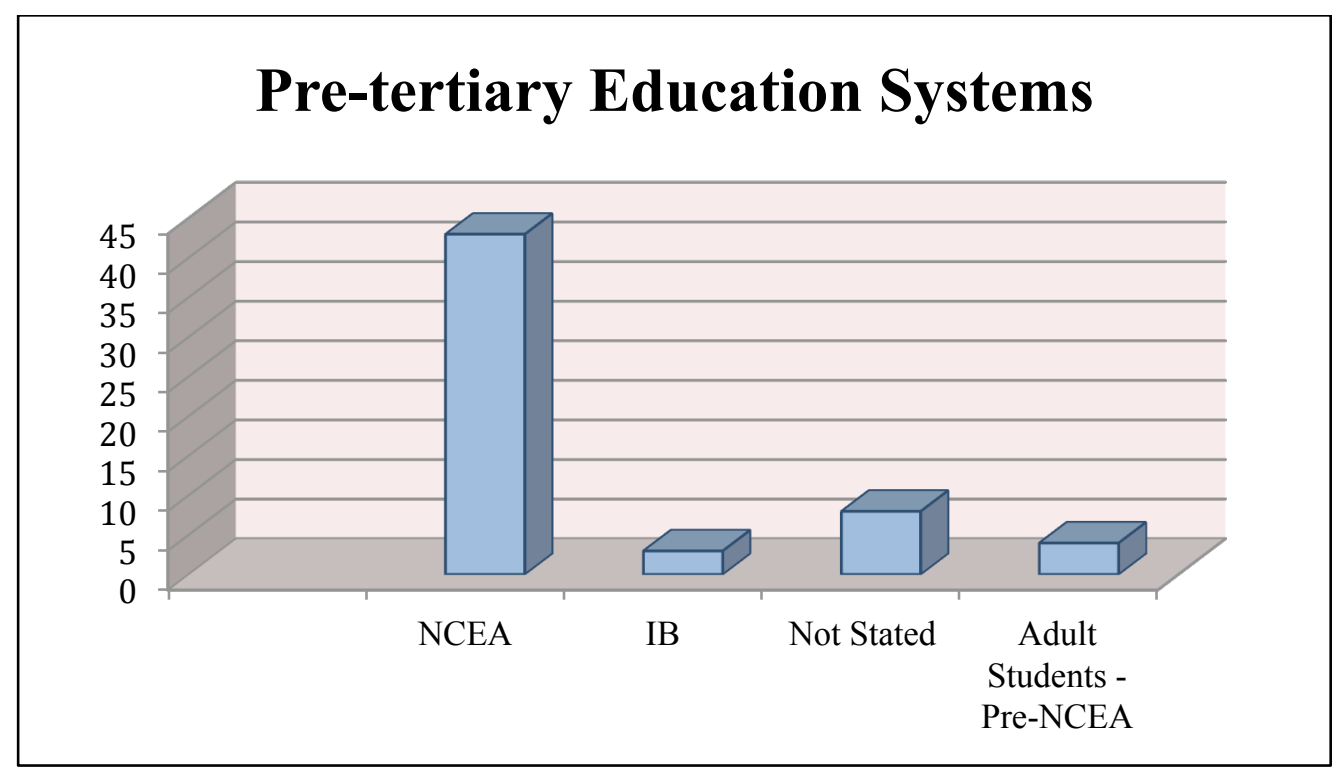

As the principal secondary school education system in New Zealand, NCEA is highly represented as the system under which the majority of performance students surveyed have previously studied. 


\section{Secondary School Students}

The two secondary students featured in this thesis completed an adapted survey ${ }^{18}$ and participated in the semi-structured interview process. They were selected on the basis that they were known in their respective musical communities as seeking to further their studies at the tertiary level. They represent both vocal and instrumental pretertiary performance experience; they represent different genders, attend different schools, and have differing educational experiences. Both study under the NCEA system.

\section{Educators}

- Information gathered from educators in Wellington has been conducted via semi-structured interviews. ${ }^{19}$ A purposive sample of secondary educators was chosen on the basis that the teaching of the principal qualifications offered to secondary school music students in New Zealand - namely NCEA and IB were represented.

- The IRMT teachers detailed in this study also have considerable involvement with music teaching music in secondary schools and with the NCEA assessment processes.

○ The student-centric approach of this project meant the interviewing of tertiary educators at Institution A fell outside the parameters of this study. I did, however, undertake a semi-structured interview with the vocal tutor of 'Ata' the vocal performance student featured in the Chapter 3 case study.

All participants quoted in this thesis have been given pseudonyms allowing for freedom of expression and opinion. The gender of each contributor remains unchanged. Following University ethics protocol, all participants are given the opportunity to view transcripts and/or withdraw their consent should they wish to do so. ${ }^{20}$

\footnotetext{
18 See appendix III pg. 103.

19 See Educator's Interview Framework, appendix VI, p. 109.

${ }^{20}$ See ethics information \& consent processes appendices IV, p. 105 and V p. 107.
} 


\section{CHAPTER ONE}

\section{A Language of Possibility - In Preparation}

\section{Introduction}

Language and empowerment are central to emancipatory pedagogy. Language shapes the way that individuals and groups 'encode' and engage with the world. It 'projects, imposes, and constructs particular norms and forms of meaning, in this sense, language does more than merely present information; in actuality, it is used as a basis both to instruct and produce subjectivities' (Giroux 1986, 59). Schools are not innocent in this respect; they produce hegemonic certainties that have inherent power asymmetries that block possibilities for agency among students (1986, 58-9).

This chapter focuses on the New Zealand secondary-school sector and the preparatory stages of the secondary to tertiary transition. Interviews are conducted with: Hugh and Lynda - H.O.D.s of Music at their respective secondary schools; also with IRMT members, Deborah and Emma who combine private studio teaching with secondary school music teaching and with assessing at performance competitions and NCEA performance recitals respectively. Through these educators' commentaries and perspectives, it is possible to get an overview of the way in which the two secondary school qualifications, NCEA and IB, are taught and conceptualised. Issues regarding the benefits of learning through creative, contextualised, and integrated processes versus systems that are heavily weighted towards continual assessments are discussed as are tensions surrounding the philosophical constructs of system design and the realities of curriculum delivery. Discussions about certain expectations of secondary and tertiary institutions highlight the importance of establishing lines of communication between these sectors. The first of this project's two case studies, which concludes the chapter, illustrates how issues concerning student identity, perceptions, and expectations of university influence future engagement with learning at the tertiary level. 


\section{Talking to the Educators}

Hugh is H.O.D of music at a secondary school that combines teaching of both NCEA and IB curricula. He has a personal preference for the IB philosophy, which he argues is more attuned to learning processes and less focused on continual assessments that he believes are more characteristic of NCEA. The value of process versus product learning is now well established in educational discourse. As David Elliott argues, for example, process is key. It is through teaching processes, he says, 'that educators teach students how to continue developing their musicianship in the future. This can only be achieved by involvement in musical problem solving and critical reflection' $(2005,12)$. With reference to an inherent link between process, integrated learning, and praxis, he comments further that students learn effectively when they are 'engaged by rich and meaningful projects; when the artistic learning is anchored in artistic production' (2005, 12). In this light it is interesting to consider the differences in the two educational systems from Hugh's perspective.

Hugh - From my experience, I feel IB better prepares the student for tertiary study. It's a two-year course, starting at Year 12 and there are no assessments in the first year other than if the school chooses to do internal ones - practice ones. The problem with NCEA is that the focus is always on getting the assessments done and preparing for the assessments and there's not enough time really to explore like you do with IB. The thing I like about the marking in IB is that it starts with the marking at zero and then you look for things and the marks go up for each point area that's correct or done well. Even if an answer in 'Theory' or 'Score Reading' is not the right answer but the logic behind it is correct and they've just come up with the wrong conclusion - they can still get a mark for it. I like this because it shows that they've actually been thinking about it. For example, one of things they have to answer in the 'Listening' paper is the context of the piece - so which era it is from. So, even if they get the answer wrong but the logic is sound, then they will get marks, which I do like because it actually rewards them for thinking. Another thing about the IB courses is that all the assessments are quite long so it's quite like university where you are given a project and you have quite a bit of time to complete it and 
there's a lot of research involved and talking to people and really indepth discussions about what you're studying. They have time to do that because it's a two-year course. For me [the problem with] NCEA is having all the assessments at Year 11 and Year 12. I just think it's wasting education by doing that - you can't teach when you're preparing for assessments all the time. Really there are only terms one to three because term four is when it all happens. My preference would be to have the assessments scrapped so you can focus on educating the kids properly - not just in music but all the subjects.

Hugh and I discussed the value of integrating various different aspects of the IB music programme. In reference to the IB composition portfolios and integrated performing components, Hugh explains the process and his belief that this sets students up well for a university environment.

Hugh - I encourage the students to write for one of our instrumental groups - so nothing that is out of the range of their playing skills. It's worked out quite well so they get to hear it performed live which is all part of the learning, because often there are sections that don't work with live instruments and they have to go back and re-write it. So, there's all this fine-tuning and [in the process] they've understood the idiosyncrasies of the instruments. That's really good learning. We have the time to do that - unlike NCEA when you're really pushed to get the composing internals done in a couple of terms - we've got eighteen months to fine tune. I think all these things are university-friendly: the way that the composing is done as a portfolio and the performing as a recital, and the way the listening paper is done in terms of the variety. [There is] so much more time than with NCEA where you're just barrelling down to get the standards done. You've really only got nine months to do them in. That's where it falls down because they can't put music in context properly in NCEA because it's so assessment focused - get the score reading done, get the theory learnt, get the solo performances out of the way. I try to relate them to each other as much as I can, but the assessments just loom all the time. I don't think that 
prepares kids for a tertiary course very well because it compartmentalises things too much; the units are all different entities.

This compartmentalisation aspect of pre-tertiary education has considerable implications for tertiary studies and I expand on this further in Chapter 2 where I detail comments from a number of performance students. Hugh reiterates the nature of compartmentalisation when I ask him whether there are aspects of NCEA that he does find valuable:

Hugh - The Score Reading in NCEA has the most value - two to three scores with questions, analysis, transposing, intervals, and terms etc. So it's basically just an applied theory paper. No listening, which is a shame because it would be nice to hear these pieces. I do play these in class if I can. I say [to the students] "you're not going to get this in your exam - but it is nice to hear it". When I'm teaching about motifs and themes, I can show them what they look like, but it doesn't really make sense until I play them examples. Then they go: "Is it that easy?" - "Is that how you do it?" It's a shame NCEA misses out that part - the actual listening to music as opposed to looking at a score. All the listening stuff - where is it? Unless you're doing Music Works, there aren't listening components in any other unit.

As our conversation continued it became clear that despite the perceived benefits of IB music, this particular system is not always deliverable and student perceptions appear to be the determining factor. I asked Hugh which system he generally recommends to students who might potentially study music at university.

Hugh - I tend to recommend IB pathway but then the problem is they [the students] have to look at the other subjects because in IB you have to do one subject from the six different strands, for example, science, humanities, English, and you have to do a second language - that's compulsory. We only offer Spanish and a lot of kids don't want to be picking up Spanish for the first time in Year 12. That puts kids off. Yeah, actually, the best musicians I have are doing NCEA music - they didn't want to do the IB course because of the workload and the second language. They're outstanding musicians and they're good academically as well. But then, I 
don't think NCEA prepares you very well for uni. ${ }^{21}$ [For example], we don't do the Aural paper as such; we do aural in lessons but we don't do the Aural paper because we're only allowed to offer twenty-one credits per subject so, by the time I've got Group and Solo Performance out of the way there's only one external paper you can do. Some boys elect to do it and they can, but I can't offer it.

It might be that Hugh is correct in saying that IB better prepares students for university music study and that it is preferable in terms of meaningful project lengths and the integration of musicianship components. Tertiary performance students Alice and Eve make comments to this effect:

Alice - I guess I found theory and essay writing easier than some of my peers because I took IB Music at high school.

Eve - I did the IB Diploma, so I did higher-level music. This was a very essay based course, so my analysis is probably quite good in comparison to NCEA students who haven't had as much practice.

The realities of delivery and the benefits of these approaches are lost, however, if the students are opting out of studying the IB curriculum for reasons of expediency or, as one student I spoke to demonstrates, if the teaching of study and revision strategies do not support the benefits of the delayed assessments.

Sophie - I hated IB; it's really hard work - and how would you like being tested on something you were taught eighteen months ago!?

The practicalities and consequences of delivery are not limited to the IB curriculum. The huge scope of credits and the broad way in which NCEA assessments are applied across the country means that certain papers, although relevant and competently taught, cannot be accepted as entry level prerequisites by the universities. Lynda, H.O.D. of music, has considerable experience with teaching NCEA music. She makes this point about the NCEA L3 Works paper:

Lynda - The thing is these kids, with us, have done Level 3 Works papers; they've analysed music, they've done the form, the tonality, and

\footnotetext{
${ }^{21}$ University.
} 
the harmony and all of that, but it's not the paper that's recognised [by the universities] for those skills. All of our kids that have done the Level 3 Works paper would be more than capable of doing the theory required for university, but the hard thing for the university is that the teaching of those things is not consistent. You know, we do the orchestral works and something that might be quite challenging but other kids [at other schools] might be doing the same thing with a pop song. So, it's hard for the university - they couldn't use something like that.

Lynda's comments open up discussions concerning some of the differing philosophical approaches to secondary school music education. The NCEA curriculum and assessment design, for example, caters for students who begin taking itinerant music lessons at secondary school or who are generally engaged and interested in music. For example, a student who begins their weekly guitar, flute, or singing lessons in Y9 can progress through the five years of secondary music tuition and classes and be confident with the assessments at NCEA Levels 1 to 3 . In this sense, the system could be described as having its basis in a 'music for all' philosophy. While this system and approach offers valuable access to numerous students, in terms of the students whose interest and future require a graduated pathway to university music study, problems exist with applying the same curriculum and assessment criteria. Lynda disagreed with my 'music for all' labelling of the NCEA system as in her school there is every effort made to cater to the different needs of all her music students. She does, however, concede that these efforts are not uniformly applied throughout New Zealand.

Lynda - The NCEA assessment bands of movement with Achieved, Merit and Excellence are so huge. So with this 'five years of tuition' well, five years of tuition is Achieved - it's not Excellence. Schools are awarding Excellences when the student is just the best student they've got, but that doesn't mean they should get Excellence it might just mean they are the best student in that year. Similarly, we are not allowed to say that an Excellence student has a chance of getting into university. But, to me, that's what it should be, getting a performance Excellence at Level 3 you should at least be in the pool of kids that might stand a chance of getting in [to university], not be nowhere near getting in. 
Ultimately, I don't think there is a national standard. NCEA is not a national standard; it's a school standard. If the [NZQA] moderation was yearly on every standard? - then maybe....

Lynda's proposal that Excellence should mean a performance standard that would equate to university-level expectations addresses only the performance aspects of preparation. It is in other aspects of musicianship, as I address later, where ascertaining a level of students' knowledge, skills, and understanding are more problematic. Regardless, what constitutes 'Excellence' in a performance is perhaps a moot point when entry auditions are required for acceptance into university classical and jazz performance programmes. In contrast to Lynda's perception about potential Excellences to years-of-tuition ratios, I also argue that a singer, for example, may well be an 'Excellent' performer after five years of itinerant tuition. Vocal performers are perhaps unique in this respect and the transition issues they can face are something that I examine more closely through the case studies here and in Chapter 3. The "bands of movement' Lynda refers to, nevertheless, have significant impact in terms of music students' successful transitions.

Lynda - I think what maybe makes it hard for the university is that every single school is doing NCEA music differently. Some are treating it as a very practical subject where theory is not done, others are treating it as a very academic course, and others are sort of half way inbetween. Actually, I think the [music] theory is quite well catered for Level 1 Score Reading is quite robust and Level 2 is quite challenging and Level 3 Harmony is a good paper. It's definitely all they [the students] need to know if they were going to go on and study music at university. So I think the theory is catered for. The aural seems to be the one that people [schools/teachers] drop and it's certainly the one that the students opt out of because they get so much of that in their own playing and whatever and it's really about what your music teacher values - what you end up learning I think.

There are some interesting issues that Lynda touches on here. The students would benefit enormously if, for example, these aural components were taught within the secondary curriculum as I argue the benefits of what students get from their 'own 
playing' is unlikely to prepare them well for what they will encounter at university. With regard to schools applying NCEA criteria differently, McPhail, discusses in more detail the effects of the resulting teacher-led music curriculum. He asserts that the current National Curriculum in New Zealand has 'little specified knowledge content and it appears to exert minimal influence over specific music curriculum enactment in the secondary school except by default in that it provides teachers with the opportunity to appropriate their own contents and approaches at a local level' (2012a, 35). Quoting from the national document directly - "The New Zealand Curriculum sets the direction for teaching and learning . . . but it is a framework rather than a detailed plan . . . schools have considerable flexibility when determining the detail" - McPhail confirms that it is 'presented as a guide rather than a prescription, leaving teachers to develop localised programmes' (2012a, 35). In his role as a NCEA moderator, McPhail has seen huge variances in the knowledge content and the skill levels demanded from one school to another. This variance, he believes, compromises the validity of the NCEA qualification (2012a, 35). In addition to concerns about the reliable delivery of equitable access to knowledge, he perceives there are concerns that unacceptable levels of variance occur where 'teachers may not possess the requisite knowledge to choose appropriate content' (2012a, 35).

Both variable delivery and assessment validity are educational issues that I pursue further particularly in relation to the case study detailed in Chapter 3. These same issues also arose during an interview with Deborah, who combines teaching NCEA music with studio teaching, in discussions about equitable processes in terms of NCEA assessments, she comments:

Deborah - There is a lot of difference in the way that schools assess and even in schools where the assessment processes are robust, the vocal and instrumental assessing is not consistent.

She argues also that a NCEA Excellence in performance is not a reliable indicator of general musicianship. She makes the following point about popular music students and piano students in particular.

Deborah - It is really hard for students to get an Excellence in piano performance, even [if they are] at Grade 8 or diploma level. But if they 
sang and had a beautiful voice it is just so much easier to make the right impression with so much less work. So you get these kids coming through and they have lovely voices and a bit of natural talent and they can perform and communicate to the audience and do all the right things to achieve Excellence but, for example, their theory knowledge is minimal. So the standards are not so aligned in that regard, are they? You can get an Excellence, but actually at tertiary level you may not 'cut the mustard'.

There are two aspects to Deborah's observations regarding NCEA assessments that are worth exploring. The first concerns the resulting tensions between the musical values and interests of teachers and their students in addition to the tensions between the more traditional (vertical) discourse of school music and the informal (horizontal) learning that is associated with popular music (McPhail, 2012). The second aspect concerns assessment validity for advanced music students and this, I believe, was aptly demonstrated at an 'Understanding the NCEA Assessment' seminar organised for registered music teachers in the Wellington region. ${ }^{22}$ Figure $\mathrm{V}$ shows an assessment schedule for NCEA L3 Performance. Based on NZQA criteria, the schedule is drawn up by the school concerned.

22 'Understanding NCEA Assessment' seminar - Wellington 30 March 2014. 
Figure V: NCEA Achievement Criteria and Assessment Schedule

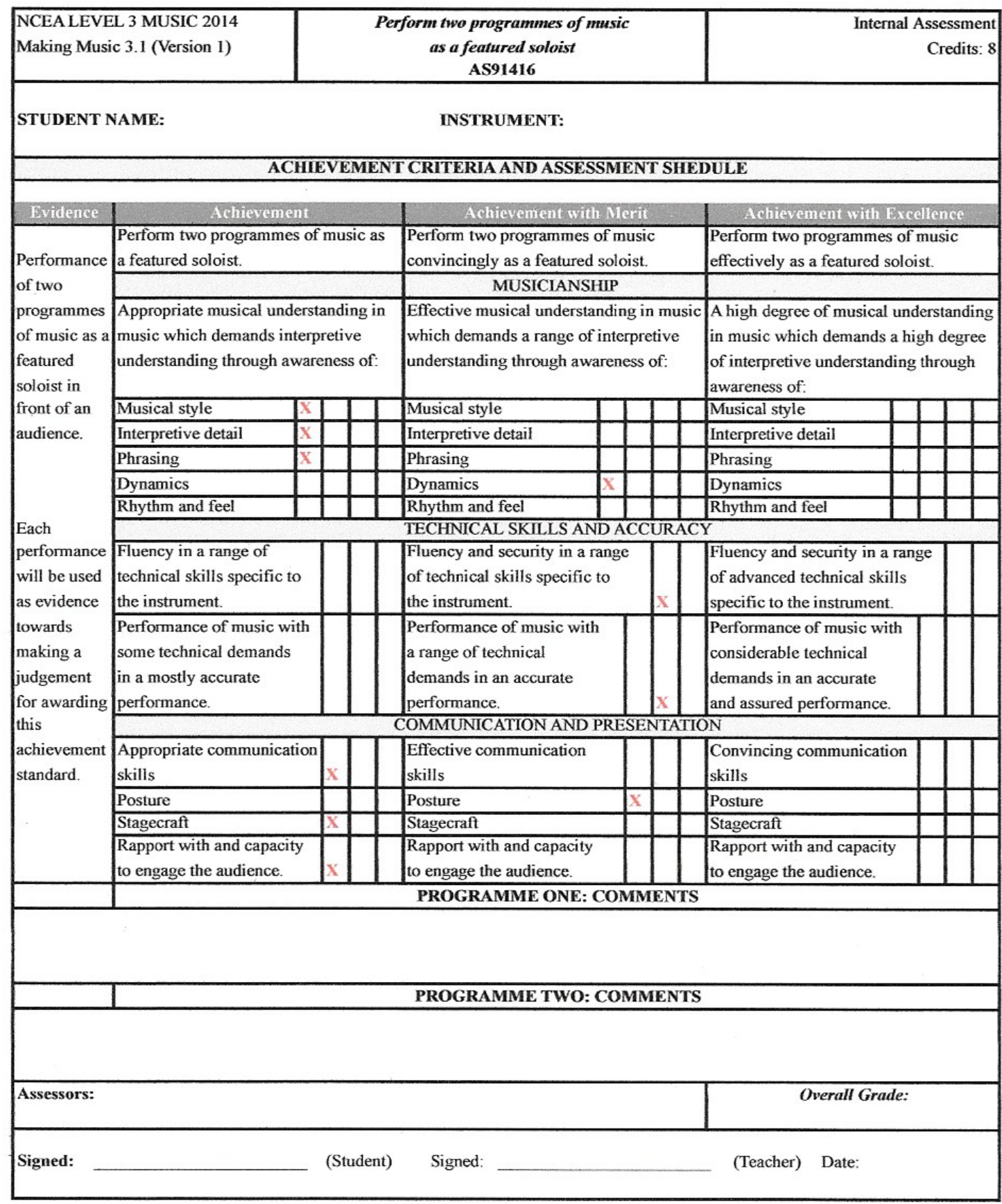

This particular assessment example concerns a Grade eight/Diploma-level pianist who decided to perform a particularly difficult work for his final L3 performance despite being advised against this by his H.O.D. of Music. Applying general NCEA assessment criteria can be problematic for students who are at an advanced level and who may be wishing to further their music study at tertiary level. As a demonstration of the difficulties posed by assessors working within these NCEA assessment criteria, 
teachers at the seminar were invited to 'mark' this student after viewing his performance on video. The 'Xs' indicate my own assessment in this seminar exercise. While it was immediately clear that the student's piano skills were at an advanced level, the performance itself was affected significantly by his choice of challenging repertoire and by a correspondingly poor performance. All the 'Excellence' criteria (right hand side of schedule), for example, musical style, interpretive detail, phrasing, fluency and security in a range of advanced technical skills are no longer options for the assessor when these characteristics are not evident in the performance. Based on the criteria schedule and given that the Achieved 'Xs' outweigh the Merits, this student should have earned an overall Achieved for his performance. Had I, or others, decided to apply these criteria more strictly, perhaps even a Not Achieved.

At the time of the actual NCEA performance assessment, the assessing panel made similar observations, however, this student was awarded with an overall Excellence despite earning few, if any, Excellence 'Xs', but rather because he showed advanced facility and was favourably compared to his peers. McPhail $(2009,17)$ has suggested, that the intention behind the NCEA qualification prescription expects teachers to use professional knowledge when making such judgements. Quoting Sadler (1989), he states that latent criteria come to the fore in the assessment process - that a 'trade-off' occurs when specific criteria are not met, but certain aspects nevertheless contribute the work meeting the standard $(2009,18)$.

Putting aside for the moment the concerns raised previously regarding reliable delivery and unacceptable levels of variance where teachers may not be in a position to make such professional judgements, I believe the more important question here is about what this assessment criteria, mediated externally by sampling, is principally designed to assess. What exactly is being assessed? More importantly, is the assessment valid? Does it provide information that validates a student's performance, the level of achievement or their potential for further study at tertiary level? The assessment, in fact, should match precisely the goals, instruction, and experiences provided to the student. I believe, in this instance, this student was essentially assessed under what Richard Colwell calls 'the imaginary curriculum that is talent' $(1999,70)$. Like most other high achieving music students, this student learns his craft outside school and it is not possible, therefore, that this assessment system precisely matches the instruction 
provided to him. I argue that there is little purpose in evaluating such students' performances, as there is almost no added value in providing easy Excellence credits. In terms of preparation, student expectations, and transition to tertiary study, easy Excellences can actually be counterproductive, as we will see further evidence of in Chapter 3. For this student specifically, there are, for example, two possible scenarios that his 'L3 with Excellence' endorsement could mean in real terms. The first might be that he fails a university audition having chosen to play the very piece for which he received an Excellence; or alternatively, he passes an audition, having once again shown facility, but then struggles with future demands of his tutors or tertiary courses in part because of his artificially elevated confidence levels.

Hugh, Lynda, and Deborah identify multiple concerns with the delivery of music curricula at the secondary level. While both the IB and NCEA systems have the capacity to prepare students for university music study, neither, it would seem, are reliably doing so. The two theoretically based secondary school qualifications accepted by Institution A, for example, for entry into their music programme are NCEA L3 Harmony or the IB Diploma. Alternatively they accept an external international Grade 5 theory qualification through ABRSM or Trinity College. In reality, of the students surveyed, relatively few Achieve NCEA L3 Harmony, as is revealed later in the entry qualification statistics, nor are they are studying IB music as it is generally only available in privately funded schools and even then, as Hugh comments, students are electing not to study under this system. As a result, the use by universities across New Zealand of the Grade 5 theory qualification attained through Trinity College or ABRSM appears to be the reliable theory qualification that provides universities with some indication of a student's level of achievement. In the application of this 'fall-back' qualification as a pre-requisite benchmark, the universities are, in effect, rejecting the music qualifications offered at secondary level in New Zealand as reliable prerequisites. Outside the performance audition process, other components of NCEA music courses are not considered in the universities' recruitment process. It is unlikely then that the universities would understand the implications of the various gaps students have in their musical knowledge. One important example, and one that has significant repercussions at tertiary level, would be the aural components that have been overlooked, for differing reasons, in both Hugh and Lynda's schools. 
The importance of these wider musicianship skills led to discussions about the students' ability to write about music. I asked Lynda what NCEA standards there were for students to write about the music they were playing or studying.

Lynda - You don't need to do any.... You can pass NCEA Music purely doing Performance, Composition, and Group Performance - that's 20 credits. It's quite possible to do NCEA music with no academic papers at all if that's the way your school tailors your program. It's just so hard, the Level 3 Works paper which three years ago, before the standards got changed, [comprised of] three essays in three hours. The students studied six pieces of music and each essay had a quote to discuss context. [It included writing about] context, elements, features, - they weren't easy and writing three essays in three hours is a big ask. Then NZQA reviewed it and now it's a short answer paper to one piece of music. I think that if we're expecting kids to write essays for scholarship ${ }^{23}$ - there are no NCEA external standards that prepare the kids for writing essays on music.

The absence of opportunities for students to be able to develop writing skills in connection to music, like the aforementioned absence of aural competencies, has significant consequences, not only for Scholarship preparation, but also for potential tertiary music study and beyond, as revealed when Lynda raises the implications for tertiary music graduates who then go on to 'Teacher's College' [the Post-graduate Teaching Diploma].

Lynda - [Tertiary] students are going on to Teacher's College and saying, "I'm a practical musician and I don't teach theory". To me, if the students are applying for Teacher's College there should be a requirement to sit and pass the Level 3 Harmony paper - because they should be able to teach it. If you are going to be an inclusive music teacher you have a responsibility to be able to teach every single kid that walks in your door.

\footnotetext{
${ }^{23}$ Scholarship is a qualification in various subjects that is offered in Year 13 for students at advanced levels.
} 
Lynda describes postgraduate students who would have sat and passed compulsory university-level theory papers and are, presumably, applying for music teaching positions in secondary schools, but are unable to teach basic harmony. This particular example provides an early opportunity to consider some of the key issues that I describe in more detail in the following chapter. They concern principally students' liminal states of understanding; that is, where students are unable to gain a deeper grasp of concepts that are needed when, as Lynda's example suggests, they are actually required to teach them. The causes of these liminal states are numerous. They can arise, for example, when students have advanced to tertiary study without, as described earlier, sufficient written or theoretical competencies, or perhaps when students face content that is beyond their current ability to comprehend, or in instances, as Lynda implies and as I soon demonstrate, where they are actually resistant to developing certain competencies they perceive as unnecessary.

Despite being proactive in ensuring robust and graduated pathways for her own music students, Lynda has experienced a number of frustrations that highlight the need for on-going communication between the secondary and tertiary education sectors.

Lynda - Many [secondary school] music departments have a heavily weighted practical program - it's less work. If you're teaching theory, you really have to plan your lessons. For us, there is the problem that NCEA is so massive and so broad that we can really make whatever programme we like so, as a teacher, there's a responsibility to make those all those pathways available. I would be really keen to get the Music Teachers Association back up and running because I think that would be a nice way to make a better connection with the universities. So, we could do things like a workshop on harmony as an association we would like that to happen. The NZQA 'Best Practice Moderation Workshop' got cancelled in Wellington because not enough people signed up to go. I'd pay for it just to have it for me and my teachers, in $m y$ school. This is ridiculous, how can the 'Best Practice Workshop' not happen? If you want to do the best job for your students then you need to be up to date with what... [pause and sigh] not enough people signed up to go! 
The effects of poor communication and collaboration between schools and between education sectors are far reaching and are certainly areas requiring further research. Currently, limited funding available for music education in the various sectors - from the classroom teacher through to the policy makers - leaves little room or resources for considering the necessary collaborative approaches that may address some of these broader concerns.

Thus far, I have considered some of the preparatory issues that impact on the transition process for music students. These often diametrically opposed issues include the benefits or otherwise of curricula that promote teaching and learning processes or those heavily weighted with assessments. Equally important is consideration of curriculum components that are usefully integrated or less so if they are compartmentalised. I have discussed assessment and system failures and variable delivery of curriculum across secondary schools in New Zealand and I have questioned the validity of performance assessments for students who do not learn their craft at school. I have also suggested some of the longer-term effects of qualifications weighted toward performance credits without the necessity of written, aural and theoretical components. Lastly, I have questioned the reliability of both secondary school music education systems, IB and NCEA, to reliably prepare students for tertiary music study.

The implications of potential systematic failure in terms of the students' future engagement with learning at the tertiary level are significant. Student attitudes to learning are affected by the way they have understood and negotiated these secondary school curricula. Further, social attitudes as well as those academic are inevitably shaped by students' school experiences and expectations of university life (Burland and Pitts 2007, 295). Michael Prosser and Keith Trigwell outline the specificities of this as four principles. Their four stages of experience or knowledge acquisition below show that what a student understands or believes about a certain subject will inform how they approach it in all its new complexities and contexts.

1. Students come to tertiary study with substantial variation in their prior experience of learning and teaching.

2. These prior experiences are related to specific prior situations in which those experiences occurred. 
3. Any new situation they find themselves in evokes certain aspects of these prior experiences.

4. The aspects evoked have subsequent substantial impact on what and how the students learn in a new situation.

$(1999,42)$.

Prosser and Trigwell's particular research orientation is to overcome the variation of prior learning experiences by 'offering students an appropriate academic orientation to their work' (1999, 27). Giroux would argue, as I have discussed earlier, that this particular approach is where the institutional focus is on reorganising rather than revisiting curriculum content. While my own objectives behind the application of these four principles differ significantly, the four stages provide, nonetheless, a useful way of understanding the importance of the knowledge gaining process. The stages point toward a central idea: students' prior experiences differ significantly depending on how and in what context these experiences occurred. Any new environment in which they find themselves evokes certain aspects of these prior experiences and thus impacts on how the students will interpret new experiences and information. It is worthwhile considering students' variable interpretive approaches in the narrative that follows. The narrative or language, in this sense, can be viewed from the perspective of how students reproduce and process learned subjectivities through the language they use.

\section{Case Study - Liz}

Liz is completing her final year of study at secondary school and intends to study vocal performance at university. She has, already, considerable performance experience both as a chorister and a soloist in a variety of contexts. She has been a member of the NZSSC and has performed in two different New Zealand Opera productions. Emma, in her role as a NCEA performance assessor, describes Liz's voice as 'one of the most exciting and promising voices' she has heard in a long time. In our interview, Liz's expectations of tertiary study are highlighted; her words demonstrate individual encoding or learned subjectivity and address related issues of identity and of confidence concerning wider musicianship skills. 
L.W. - So, if you had a 'wish list' about what doing a music degree might offer you, what would be on it?

Liz - Well to improve my singing obviously, so to get to that next level, so I mean, I hate talking about myself, this is so bad [laugh]. I feel like I am at quite a high level at the moment and that's because of the amount of back-stuff I've done. So, like I've done all this choral work and solo performances and stuff so I think I would be at quite a high level. So, I think I would like it if they could just push me that extra bit because I feel like I need pushing to get to my full potential. I have quite a mature voice at the moment and to just push me that to that extra level would be amazing. Um... honestly, it's more about technique for me. I mean I have pretty good technique at the moment, but it would really cool if they could teach me some new ways to... [pause] you know, some different things ...

These comments, which I expand upon later, led to questions about some of the nonperformance components of NCEA music. For example, in response to her lack of enthusiasm regarding learning music theory I asked:

L.W. - So what is it about theory that you find difficult?

Liz - I think it's just that, (sigh) ... I don't really know. I think it's just like a mental block type of thing, I feel like it's just because when I was taught it back in the day, it was so strenuous and boring, like, they would just teach it to nail it in your head you know?

L.W. - So, you're not really seeing the relevance of it?

Liz - No, because I can read scores easily, you know, time signatures, key signatures, fine, dynamics, you know, tempo markings, everything that's fine with me like, I can sight read - it's fine. It's just the fact that they take everything out and make you do something that's irrelevant and that, like for me, obviously, because I perform solo, to me it's about the emotion - like most of it is about the emotion for me, but that's probably because I'm quite an emotional person. 
L.W. - I think [smiling] maybe most singers are.

Liz - Yeah, you really have to touch something deep down to get... I mean because it's all about the emotion, you've got to show what the composer is trying to portray and it's very hard to tap into that if you're not in touch with your own emotions. So I find that theory, taking it out of that emotional context, kind of ruins it for me. But, then with [NCEA] Music Works and stuff we learn about the background and the emotional aspects of it - that's what I really enjoy, the fact that we watch all these movies and go through all these documentaries about why these people wrote these pieces and it's so interesting for me, but then taking it out and making it emotionless ruins it and I'm, like "I don't want to do that". Arrggh - it's boring! I just know that if I can't relate it back to the essence of the music then I just don't engage. I mean we all learn differently - there are some girls in my class who do amazingly at theory because they are very... [pause] you know, they're not focused on the emotion they are more focused on the practicality of the music and they can just sit there for hours ...

The language that Liz uses here provides an opportunity to evaluate future learning engagement based on her present perceptions. It appears, for example, that her emerging identity as a vocal performer is intrinsically linked to the idea of music as emotional expression. This particular view is likely linked to her understandings and experiences of vocal stagecraft. However, it seems that, for her, 'music as emotion' has become an over-arching ideological construct. Moreover, it appears to actually legitimise her disengagement with other ways of thinking about music.

Figure VI: Liz's ‘Music as' Continuum

$\leftarrow$ Rational 'Music as' Continuum Aesthetic $\rightarrow$

Music as 'Practicalities'

Music as Emotion 'They'

'Me'

'Nail it in your head'

'Emotional' 
Liz has set up a conceptual binary by defining music as an aesthetic and emotional experience at one end of a continuum and as a scholarly and autonomous analytical exercise at the other. Additionally, Liz's perception of 'they' and 'me' suggest a further binary concerning identity. While I cannot adequately communicate her particular tone, her comments about the other girls at school - who are, according to Liz, 'focused on the practicality' of the music - also suggests that these girls are not as emotionally connected to the music as she is and, perhaps by extension, not as musical. Liz's lack of confidence in the more theoretical demands of music, however, is masked by her confidence and identity as an emotional young singer who is already at a 'high level' and has a 'mature voice'. This idea is confirmed by her response to a later question:

L.W. - So, what's in your future, where do you want to go with your singing?

Liz - Ideally I'd want to be an opera singer but that's kind of far fetched and stuff, but that's honestly - I've loved it since I was, like eleven and that's so weird for an eleven year old to listen to Puccini instead of Beyoncé, that's just weird! ... Opera just touches something and I want other people to feel that. It would be just so amazing to be able to get on the stage at the 'Met' and just sing and everyone just being, like "ahhhh".

I've thought of teaching, but because I don't have that knack with theory, I just don't think that would be beneficial to the student - and if I was trying to teach them it would be like "she's nuts - she's just too emotional - we can't do this" [she laughs].

In this 'after-thought', perhaps the product of her assumption that I might expect different considerations of her career options, Liz literally imagines future students responding to her inability to teach music theory. In doing this she dismisses it as a possibility, and more importantly, she suggests perhaps that her emotional sensibilities (something that she perceives as required of an opera singer) preclude the necessity of engaging with such practicalities. It is understandable that Liz is focused on her desired future as a performer, but what is more concerning is that her expectations of tertiary 
study are that it will enable her to achieve this goal through lessons in advanced technique and little else. She comments:

Liz - I want to have a fresh start there [university] ... to be enjoying what I'm doing and I want to have just one subject that you're doing instead of six or whatever; just one solid thing that you're focused on.

Liz's desire to focus on 'just one subject' is a reflection of her increasing disenchantment and frustration with her secondary schooling. It is also, however, an indication of her lack of awareness of broader aspects of a music degree education. Heading into tertiary study, Liz's strong identity as a musician, albeit a musician in training, has particular implications for how she will, or will not, engage with her tertiary music studies.

In a thesis concerning the relevance of theory in pursuit of becoming a musician, Laila Kteily-O'Sullivan makes this very observation about identity in this context. 'Undergraduate [music] students', she comments, 'already consider themselves musicians when they enter tertiary study - they just expect to become better' $(1996,3)$. In reference to Elliott's 'knowing how versus knowing what', she asserts that performance students' learning is typically action based - they learn by doing. At university, she says, they will inevitably face a more formal, technical, and analytically based lecture room that they will, in all likelihood, perceive as problematic and irrelevant. In effectively identifying themselves as musicians and not academic students, expectations placed on them are often met with resistance (1996, 3-7). 


\section{Student Disengagement and Identity Perceptions}

Figure VII: The Binary Flip Switch of Disengagement

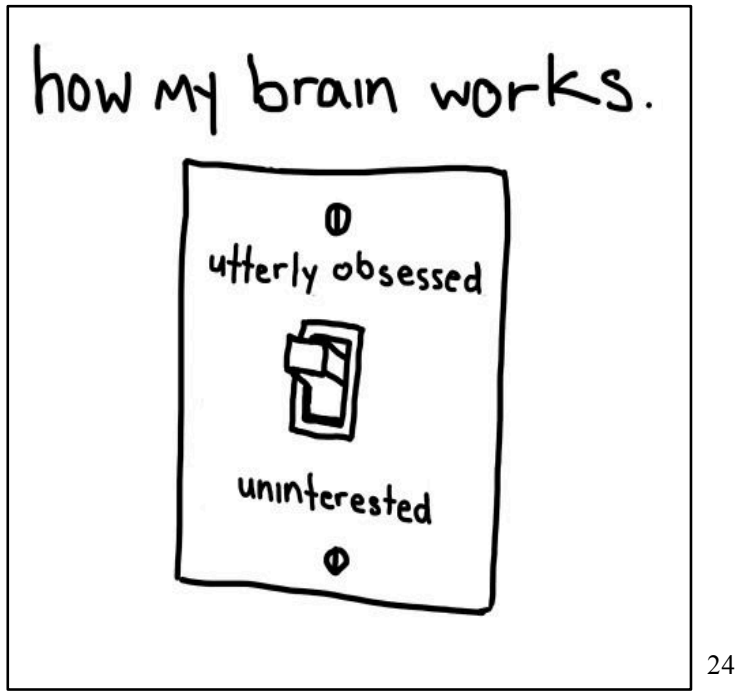

In searching for a suitable image to accompany a presentation on this subject, I came across this image online. It is used in the context of describing, with equal amount of humour and seriousness, how one man perceived his particular neurological condition. I suggest that this binary flip switch quite accurately reflects how Liz is engaged with her music and with her schooling and indeed how many of the university performance students surveyed have talked about their engagement with their tertiary music studies. The passionate language used by many of these students to describe why they are studying music, for example, in addition to their dismissal of theoretical and written components of their degree are perhaps an indicator of the strong focus they have on performance and the little investment they have in other degree requirements.

Detailed below, and representative of a significant proportion of performance students surveyed are:

- Emotionally descriptive reasons in answer to the survey question that asked why they chose to do a music degree:

\footnotetext{
${ }^{24}$ Image available from - www.aboywithawholeinhishead.info
} 
Ben - Music quickly became the most important and influential area of my day-to-day life and I decided that study in the field would be a fabulous way to continue the pursuit of a subject that I love!

Lisa - Because it is the subject I am most passionate about.

James - I always enjoyed music. I had a passion/dream to become a composer. I'm good at other things like maths and chemistry but decided to follow my heart.

Sarah - There is nothing else I can see myself pursuing for the rest of my life.

Gemma - I only ever wanted to sing and I believe you should do whatever you dream to do.

Stuart - I was in a dead-end job and was encouraged to study in pursuit of my passion - not sure what I'll do afterwards but we'll see what happens!

Kate - Emotional fulfilment.

Penny - Music is my life, I want to be on the stage!!!!!

[Exclamations accurately represented]

Tess - Doing a music degree is very important to me, as music has been part of my life since I was six years old.

Angela - I have wanted to become an opera singer my whole life, and university study was the best way to go about this. I love it!

Luke - Purely, because I cannot do without music.

- Representative comments about general tertiary study expectations and perceived value of some university music courses they have done or are doing:

Eve - I didn't love theory, I think the analysis paper is good but I can't really understand why we study counterpoint as performance majors - I don't know if I'll ever use it. 
Alice - [Various music history/musicology papers] while interesting, are not necessary for a career as a performer. ... I was expecting university to be more like a conservatory ... I didn't expect there to be so many essays.

Olivia - I assumed a performance major would be more tailor-made and would actually entail a lot more actual performance.

Gemma - I only like music classes that actually relate to me becoming an opera singer, otherwise I find them irrelevant and I can't enjoy them. [I found the least relevant subjects were] most of the theory and history papers I have taken except 'Introduction to Opera', as they haven't really taught me anything that I am going to remember in the years to come and that I will need to become an opera singer.

Hanna - Theory and history - I think these classes are useful for people that want to teach music at school and for people that want to write about music.

Rick - One paper I did seemed to exist in its own little vacuum. I can't imagine the knowledge I gained from the course being valuable in any other context.

Ostensibly, these students are communicating a rather disheartening summation and dismissal of the broader aspects of musicianship. A more subtle reading of their language and implied meanings is possibly revealed in the following example. Jeff, an instrumental performance student who is introduced at greater length in the next chapter, had this to say about a compulsory 100-level musicology paper. 'Relevance' is usefully contextualised in this exchange.

Jeff - There are still aspects I found completely irrelevant for myself, but certain studies I found irrelevant I found fascinating and I can still tell you bits and pieces that we listened to - just because it was so weird.

L.W. - It's interesting that you say on the one hand that it is fascinating and on the other irrelevant. How do you...? 
Jeff - Well it was fascinating because it was different and I think that's the point. But then it's irrelevant unless you are going to specialise in that area.

L.W. So the way you've used the word 'irrelevant' really means that you don't see how you personally are going to use that information, but you don't mind having learnt it?

Jeff - I don't mind having learnt it.

This cautionary re-contextualising of language aside, the students' observations over broadly support Liz's perceptions and are examples of how language can reveal student subjectivities concerning their musical identities, education and development. The comments confirm the idea that how students talk about themselves and their musical practices is an opportunity to understand how they will approach new learning situations. To reiterate, students' attitudes to learning are shaped by their school experiences and their expectations of university study. Although we should assume that students do not share the same 'musical habitus' and that, as Thomas Regelski suggests, they have different objectives behind their engagement with any subject, we do need to acknowledge the power of language and the way that it projects, imposes, instructs, and produces subjectivities $(2004,16)$. In this sense, despite students' diverse practices, this research shows that certain pre-tertiary systems and practices within New Zealand have resulted in significant homogenous subjectivities.

It is worth observing an example of these homogeneities from the perspective of another secondary school student. Karl is an exceptional young instrumentalist who, like Liz, has already had a number of opportunities to perform solo throughout New Zealand. Karl is in Y12, however, as an accelerated student he has completed NCEA L3 (Y13) qualifications for which he has received Excellence grades across his subjects. I asked him about his expectations of university music study:

L.W. - So, what do you imagine that you will study at university - how do you imagine it will be?

Karl - Well, I'm doing performance and so would focus on the orchestral stuff - that's where I want to go - play in orchestras. 
L.W. So, outside of your performance papers and tuition, what else do you imagine that there might be or what else might you be interested in?

Karl - Ahhh... I don't really know what's available really... in terms of written papers you mean?

L.W. Yes, or interest papers - what other interests do you have outside performance?

Karl - Well...[pause], if I'm digressing outside of the performance aspects, I'm really interested in maths, and I've always been interested in how maths exists within music. Like, $\mathrm{La}$ Mer was written and some mathematician managed to prove that it fits a whole bunch of mathematical principles in terms of the way he [Debussy] writes and I'm quite interested in how that all ties together.

L.W. So do you see analysis as something you could look at in that way? Is analysis something that you enjoy doing?

Karl - Yeah, but only within the realms of contributing to performance.

It is interesting that Karl resisted discussing aspects of music study that fall outside his conception of a performance degree. His comments suggest, not only a reluctance to talk to me about these aspects in any meaningful way, but also reveals that he has constructed real and conceptual barriers that may impact on his future engagement with the more theoretical aspects of a degree course. It is possible that, like Liz, Karl has experienced theory tuition that was 'nailed in his head', disconnected from his performance repertoire, and thus removed from any meaningful context. Despite being very academically motivated and spending hours immersing himself in orchestral music at home, it is perhaps not surprising that he has considered it unnecessary to take his theory qualifications beyond the minimum requirement of Grade 5. On the presumption that theory would be an easy task for him, I asked him directly why he had not pursued theory to a higher level:

Karl - [smiling] Well I don't really need to.... 
This summation of need appears to be echoed by the majority of performance students surveyed. The following graph is based on responses to the survey question that asked students to detail their highest level of pre-tertiary theory qualifications.

Figure VIII: Performance Students' Highest Pre-tertiary Theory Qualifications ${ }^{25}$

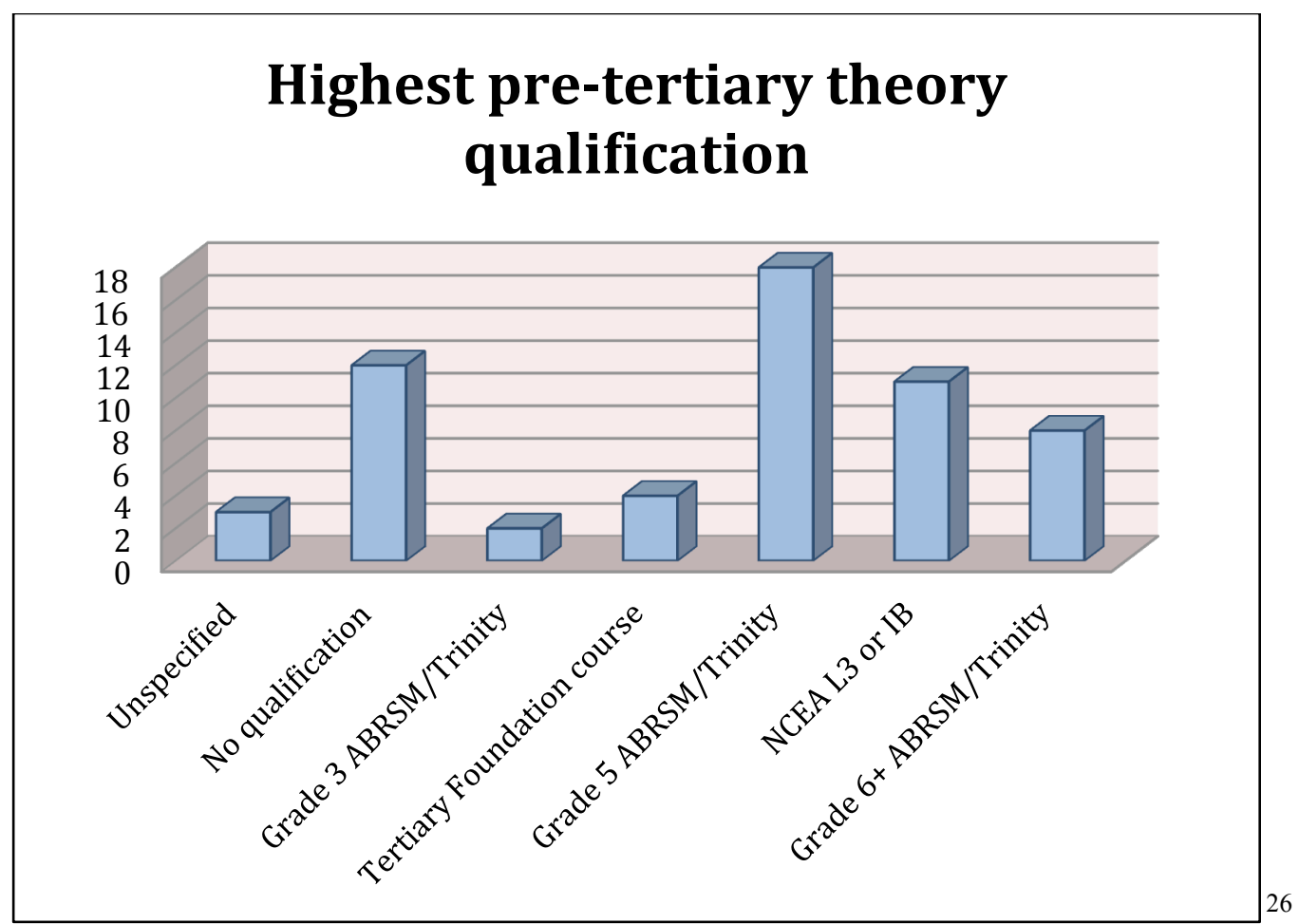

What students perceive, or have been told, they 'need' is very apparent. As stated earlier, a Grade 5 theory qualification is the minimum requirement for entry into all classical music degree courses across New Zealand; it is also a prerequisite for Grade 6 practical exams through ABRSM and, until relatively recently, Trinity College. As Figure VIII indicates, the numbers achieving qualifications beyond this drops away considerably. The majority of performance students have this exact qualification and while these aforementioned prerequisites may appear to be sufficient justification for

\footnotetext{
25 This information is subject to the students' perception of what constitutes the highest qualification. The 'no qualification' column includes students who have completed various level theory studies e.g. Dulcie Holland series, but who have not sat any formal exams.

${ }^{26}$ The students identified in the first two categories, in addition to the Grade 3 category, would have most likely qualified for entry into Institution A by completing the university's Theory Foundation Course or passed the 'Tertiary Placement Test' at their performance audition. This TPT test is designed to test at an approximate Grade 5 level, however it is not a recognised qualification in itself.
} 
this, there are other aspects to these statistics that I think are worth exploring. I suggest, for example, that they show that there is little investment by music teachers - school and studio - in developing and extending theoretical competencies other than those required for performance or those specified as university entrance requirements. Where this is problematic, and symptomatic of a possible lack of awareness between secondary and tertiary music educators about each others' course content, is that it is commonly understood, at least by the university students surveyed, that the first year theory papers, as they exist currently, demand knowledge well in advance of this. The representative comments below are from performance students, all of whose pretertiary theory level was at Grade 5 or above.

Gary - Theory taught at university increased dramatically from entry requirements. I was soon left behind and disinterested.

Eve - The theory classes would be the most difficult, because they were teaching something completely new even if you'd done quite a lot of theory before.

Amanda - I felt as if the theory at university was completely different to anything I had done before. It was a huge step up and the course went so fast ...

Paul - My feeling is that Trinity College and ABRSM qualifications better prepare you for university study. It would seem inconceivable for someone who has not had private tutorage to enter a university performance major.

Dave - From my experience coming to university to study music is a big step from secondary school study ... there is no emphasis put on the importance of theory and understanding harmony and counterpoint. I gained some experience through NCEA but it was very limited and optional.

A further consideration, and probably the most significant about these pre-tertiary qualification statistics, is a perpetuation and consolidation of compartmentalised approaches to teaching music - a practical versus theoretical ideological divide. This compartmentalisation does not benefit either educators or students. Hugh, for example, 
expressed his frustrations with this when he described the lack of time available in a very assessment-based curriculum that separates the various aspects of musicianship. Liz and Karl also describe disinterest with components that have no relationship to their performance repertoires. This compartmentalisation is well established and difficult to resolve without significant efforts by educators to provide relevant links by finding effective ways to incorporate the theoretical and performance aspects of musicianship.

Deborah, the private studio teacher introduced earlier, provides a further example of the dilemma. It arose in the context of talking about difficulties faced by tertiary students focusing on popular music.

Deborah - I don't think that you should be able to go on to university even if you are a great musician without having some knowledge of harmony. You can't just get by on what the guitar chords are.

Yet, the way in which she conceptualises the theoretical components in her own teaching practice is revealing.

Deborah - When my students pass Grade 5 [theory] I always start them on the Grade 6 book, but it actually takes up too much lesson time. It's hard enough getting them to Grade 5 in a one-hour lesson. To teach beyond that and try to get through the repertoire - it actually becomes a bit of a relief when you don't have to include theory in the lesson. I have never put a student through a theory exam higher than Grade 5 because I don't have the time to teach it. 


\section{Discussion}

The issues and practices summarised earlier in this chapter focused on the pre-tertiary factors in the transition process. They concern, for example, curricula heavily weighted with assessment, compartmentalisation or absence of musicianship components, validity of performance assessments, in addition to the consequences of schools across New Zealand applying NCEA criteria differently. These factors all need to be considered in relationship to student identity and perceptions that are revealed through the language they are using. This language makes clear the effect of certain pre-tertiary experiences, expectations they have of university study, and the resultant attitudes to learning. I suggest, for example, that the 'binary flip switch of disengagement' is a formidable hurdle for educationalists as I believe the benefits of a broad musical education based on aspects of holistic musicianship - something that is perhaps retrospectively appreciated upon the completion of a music degree - can remain forever elusive to those students who make minimal investment in it. I can think of no stronger argument for early-integrated and meaningfully connected music study and practices. As Joseph Kerman has argued, for example, 'The potential of analysis is formidable, if it can only be taken out of the hothouse of theory and brought out into the real world' $(1985,18)$.

Burland and Pitts' belief about the 'strong transferability across the domains of performance and academic confidence' is also worth challenging in this context. Whilst instances in which such transferability may be observed, it is important not to over-simplify this relationship. In fact, my research appears to suggest that, for students, skill and confidence in their musical lives and the associated formation of musical identities can result in a determined focus that precludes engagement with other ways of thinking about music. Addressing these concerns is only possible through understanding the implications of pre-tertiary environments, by integrating aspects of musicianship, and by making meaningful connections between secondary and tertiary knowledge. 


\section{CHAPTER TWO \\ Troublesome Language - On the threshold}

\section{Introduction}

Matt - The theory classes have definitely been the most difficult for me. My theory knowledge gained prior to university study has helped me in a huge way, but these classes took the skill required to a new level. Although most of the information required for the course is in the textbooks, the books are very hard to read as they have very technical language not made for students, such as an easy step-by-step approach to certain concepts.

Troublesome language is one of three elements identified by Jan Meyer and Ray Land inherent in threshold concept acquisition. The troublesome 'technical language' described by Matt above is new and discipline-specific terminology that can present potentially familiar material in ways that are conceptually difficult for the student. These language difficulties can be compounded if teachers attempt to clarify their subject by using 'further troublesome language, metaphors, and concepts in an endless play of signification' $(2006 \mathrm{~b}, 14)$. The effect of this 'endless' layering and delivery of troublesome language is perhaps captured by Gemma's words below:

Gemma - Theory was the most difficult subject because it went very fast and there was no time to catch up if you missed something or didn't understand something.

This chapter takes a step back and discusses the secondary to tertiary transition within the theoretical constructs of threshold concepts. It builds on previous discussions and reintroduces and theorises examples used in Chapter 1 in this context. Also, in reference to issues raised in Chapter 1, I discuss the complexities inherent in threshold concepts, which are compounded by the variable ways in which the NCEA music curriculum is delivered and by the effects of poor communication between the secondary and tertiary sectors. Data from interviews provide a student perspective of transitional challenges and, as a result, two crucial aspects of transition are revealed in the process. Firstly, the nature and importance of what the students first encounter in 
their 'make or break' year and secondly, the problematic aspects of assessment-based learning.

\section{Threshold Concepts}

The first year of tertiary study is considered the 'make or break' year. What concepts are understood, what knowledge is attained or what friendships are forged in this year will be the determining factors in student persistence or withdrawal (Pitts 2004). In this respect, threshold concepts could be considered to be at the heart of the transitional process. Meyer and Land describe a threshold concept variously as a portal, as new core knowledge, or as a conceptual building block. The acquisition of such a concept, they maintain, is transformative for the student and leads to a significant shift in perception and subjectivity. Without this knowledge or understanding the student cannot progress (2006a). In addition to 'troublesome language' described in the introduction to this chapter, the two further integral aspects to this knowledge acquisition process are 'liminality' and 'troublesome knowledge'. Liminality is the state of in-between where students oscillate between earlier (less sophisticated) knowledge and a deeper understanding of what their lecturers and subjects require. If students remain stuck in this liminal space, knowledge for them can be superficial, limited, or partial. For example, the post-graduate students described earlier who appear unable to teach secondary school theory despite having passed university theory courses.

The second aspect, troublesome knowledge, is knowledge that is often protracted and conceptually difficult or even, as Meyer and Land describe it, 'counter-intuitive or alien' (2006a, 4). Eve and Amanda's comments about university level theory reintroduced from Chapter 1 exemplify this.

Eve - The theory classes would be the most difficult, because they were teaching something completely new even if you'd done quite a lot of theory before.

Amanda - I felt as if the theory at university was completely different to anything I had done before. It was a huge step up and the course went so fast. 
Understanding threshold concepts is important in assisting educators to identify appropriate ways of modifying or redesigning curricula in order to enable students to negotiate their transitions more successfully (Land et al. 2006, 205). There are significant challenges both in this and in responding to the pre-liminal variations that students may have in approaching a threshold concept. As Meyer and Land suggest there are considerable methodological and conceptual issues that require further research $(2006 \mathrm{~b}, 29)$. In this respect and in their own collaborative research, they provide extensive statistics and examples that cover subjects including history, economics and mathematics - subjects that are generally standardised at the secondary level and that have graduated pathways for students intending to study at the tertiary level. When pre-tertiary subjects are less standardised, as discussions concerning delivery of the music curriculum in the previous chapter suggest, then responding to pre-liminal variation is compounded further by complexities inherent in these same variables. This response is difficult yet absolutely necessary when one of the first considerations in reviewing course design is attention to the sequencing of knowledge acquisition in addition to recognising the processes necessary to prepare students successfully (Land et al. 2006, 198). Thus, the challenge for tertiary music educators goes beyond ascertaining students' understandings or subjectivities; rather, it requires them to come to terms with, and respond to, students' entirely different starting points of knowledge.

Lynda (H.O.D introduced earlier) provides a specific example of where this sequencing of concepts is potentially compromised by inadequate communication channels between the secondary and tertiary sectors. In her school, students are being taught to notate chord inversions using a, b, and c, for example Vc, whereas University A, for example, requires the students to understand the basis and use of numerals, for example, V ${ }_{4}^{6}$. She comments:

Lynda - We didn't know this so we were not teaching it to our kids - I don't know if NZQA knows it either, so there's a disconnect between what we are teaching and what the university are doing in harmony because we didn't know anything about this. I don't know whose responsibility it is as a group of music educators - actually, it is a collective responsibility; I mean it's not rocket science! 
Lynda is rightfully suggesting appropriate communication between the secondary and tertiary sectors in addition to the qualifications authority NZQA. She is also perhaps suggesting, in this instance, the standardisation of terminology. This is not necessary, however, if the new terminology is considered conceptually different and an important threshold concept. What is beneficial, however, is awareness and communication between the secondary and tertiary sectors; if lecturers are aware of how inversions are taught at secondary level then he or she can ease the transition by considering the students' starting points of knowledge and thus prepare them successfully. Essentially, educators 'need to know more about pre-liminal variation of any student cohort given the obvious implications this would seem to have for subsequent retention and progression' (Land et al. 2006, 203).

What we know, in terms of the implications of course design and evaluation, is that we need to help students overcome barriers to learning; we need to know what makes some knowledge areas more troublesome than others. In this, issues of identity can be significant. On the premise that a threshold concept is a 'way of thinking' distinctive to a discipline (Davies 2006, 74), 'learners who do not think of themselves as learners of economics [in this context we might substitute 'music theory' for 'economics' as an example] are likely to face particular difficulties regarding binding together aspects of a subject' (Land et al. 2006, 195). If we reconsider Liz's reluctance to engage with theoretical aspects of music study, which I have suggested is largely due to her identification as an emerging performer rather than as a potential tertiary music student, then we may begin to understand how particular terminology and concepts might be troublesome to her. These new terminologies are intrinsic to the way, for example, 'music theorists' think - not the way she thinks. In order for students to overcome troublesome barriers they need to be prepared to let go earlier comfortable positions. New knowledge demands an integration of ideas and this 'requires the student to accept a transformation of their own understanding' (Land et al. 2006, 196).

The introduction of a threshold concept is not just a matter of simplifying material for the student. Simplified material can actually operate as a 'false proxy' leading students to settle for a naïve version of an important concept $(2006,203)$. What is essential is recognition of when students have sufficient knowledge so that it is actually feasible for them to develop an integrated understanding (Davies 2006, 81). This is possible through the introduction of specific characteristics of a concept as well as guidance in 
the ways in which these can be applied. Students need to be assisted explicitly and it is paramount to consider what it is that they first encounter - first impressions matter (Land et al. 2006, Davies 2006).

\section{On the Threshold}

As students approach their 'make or break' year and the associated threshold concepts, their academic preparation, as discussed previously in Chapter 1, is inevitably shaped by their school experiences. Jeff, a university instrumental performance student, was, like Karl, an accelerated student at secondary school. He has interesting perspectives about the benefits or otherwise of secondary school preparation through NCEA. He describes it as a system where students can negotiate their way through curriculum requirements without, he believes, learning valuable lessons that can be provided through experiences of failure.

Jeff - It [NCEA] is far more confusing than necessary and in some cases it's so easy to "Achieve" that it's not putting any work on the student. Also there's this, and I appreciate that lack of emphasis on failing because it's not a very positive outlook, but in some cases I feel like the complete removal of the idea of failure is one of its biggest flaws.

L.W. And so, what do you think are the implications?

Jeff - It means that if you get a "Not Achieved", which is essentially a Fail, it's a softened version of the big fat $\mathrm{F}$ you would get normally. It means that students are content to get that even though they're not achieving anything - not achieving any of the credits. It doesn't give them that real push to want to get anything better than that. They're not being told they've failed, they've just been told that they haven't "Achieved" that particular standard. The students can just negotiate through the credits they want to get and I feel that that is a huge flaw in the system.

What is at risk with more traditional educational models that demotivate students by giving 'big fat Fs' is the support of students within a system that rewards them for 
their strengths. It is interesting, for example, that the same 'flawed' system actually benefitted Jeff by allowing him to negotiate certain difficult challenges of his own. Although a high achiever in general, Jeff has a particular fear of exam environments. He comments:

Jeff - I used NCEA hugely to my advantage, which is what I think you should be able to do - to use it to help build on areas that you are interested in. It wasn't that I wasn't good at harmony and didn't want to do it, but I have a strong passion against sitting exams. I really don't like doing them. I'm not an exam sitter. I'd rather get on the performance stage than sit in a three-hour exam. I made sure to avoid all external assessments so everything I did was internally assessed. So, I could work at it and focus on it and present it to my teacher to critique and get verbal feedback, which I much prefer. Then you get a mark that hopefully represents your real efforts.

Acknowledging a student's 'real efforts' would seem paramount in any assessment system. Burland and Pitts' contention that the benefits of confidence in one area of expertise are transferable in another operates well in a flexible system that allows a student, like Jeff, to negotiate his way through it. The benefits of such a system, however, need to be balanced against aspects of the system that have the potential to leave the student underprepared for tertiary study. To reiterate, McPhail's research perceived 'considerable under-specification of knowledge content and progression' due largely to NCEA's flexible framework, which he believes ultimately hinders student learning (2012b, 318). It is, as Burland and Pitts suggest, an area for further enquiry and something that I address in the next chapter. At this point, however, it is worthwhile considering aspects of performance students' school experiences and their perceptions of how well they feel they are, or are not, prepared for tertiary study. When asked to reflect on their general preparation many students felt underprepared for the level of work at university irrespective of their level of academic or performance experience.

Celia - I feel that because I had a lot of music study before I came to uni, I was more prepared. However, the technical words etc. are a bit of a shock when coming from secondary level study. 
Daniel - I felt very underprepared for university study as high-school music had very little theory training whilst university was dependent on lots of prior knowledge.

Matt - I don't think NCEA music is the best that it could be. In my case, it has been extremely fun and interesting, but most of my knowledge has been obtained outside of school. I always felt that I was not being catered for at school. Being at diploma level and far above everyone else in my class, I felt held back and unable to extend myself. I believe the NCEA system does not cater to this level; it could have just been my school, but I always seem to get easy Excellences, by just performing my diploma repertoire, therefore it doesn't really help the people wishing to study performance at university in my opinion. ${ }^{27}$

Gill - I don't feel like I have ever been taught music like this before. It was quite a shock to go into this environment. I don't feel like secondary school prepared you for tertiary study.

Sue - I don't find the theory [at university] to be completely unbearable; it is actually quite nice to have a challenge compared to school where I was the only person who understood music theory properly. I love everything about music and theory is a fundamental part as it links into so many other aspects of music. My passion for music though is what keeps me going when my tertiary study seems too hard or overwhelming.

Paul - I did not feel that NCEA L3 prepared you for a performance degree. It is very easy to attain Excellence in performance at high school and does not prepare one for the amount of work in short time frames that university expects.

\footnotetext{
${ }^{27}$ Although similar in circumstances, both the student and the school differ to those introduced in the marking schedule example in Chapter 1.
} 


\section{Threshold Concepts Widened}

The last example expresses concerns about the 'amount of work in short time frames' and is an area of transition that I explore further in a conversation with Jeff where he expands upon his own transitional challenges. It is a reminder that knowledge acquisition needs to be considered in the context of the huge adjustments that most first-year university students have in this period of their lives. There are numerous areas for which students suddenly need to take responsibility - for example timetabling lectures, lessons, and tutorials - in addition to those responsibilities that are less structured - such as making time for study, for writing, as well as the locating of both new places and unfamiliar resources. All this needs to be handled on top of managing personal daily routines away from the students' home environments. Time management, considered as part of these larger transitional hurdles and conceptualised as a new challenge requiring significant shifts in perceptions, could in itself be considered a threshold concept. Jeff's comments below support this idea.

L.W. - What do you think is the most difficult thing about the transition process for music students or for you personally?

Jeff - Freedom: it's the hardest thing to transfer from which is why high school does not prepare you at all. You go to high school from nine a.m. to three-thirty p.m. and then you come home and have your freedom every single day from nine to three thirty. You get to university and you get a list of classes and get told to "have fun" or "good luck" and all of a sudden you don't have to go for six hours a day. You've maybe got one class on Monday; you've got three classes on today, no classes on a Wednesday, maybe an hour on Friday, and the whole weekend off. Then that totals six hours of classes in the entire week and you go "what do I do with the rest of my time"? That is the hardest thing about transition.

L.W. - How long do you think it takes to adjust to this? How long did it take you?

Jeff - I think it took at least all of first year for me to work out how to manage my time in a productive way, then, in the second year and third 
year I was able to refine it a bit and maybe I'm just starting to properly get the hang of it in fourth year. It's because it's ingrained in you for your entire pre-tertiary education since you were five years old. So, like, a good thirteen years of your life you've got a nine to three regime five days a week for forty weeks of the year. Then you come to university and have been told you've been prepared for this and all of a sudden all those boundaries get stripped and you have all this freedom - not necessarily freedom, it's like you are then able to control your own life and that's something that we're not taught. We never come across this freedom anywhere in your pre-tertiary education. And it's like, "wow, what do I do with myself".

As Jeff comments, these time-management skills are often counter-intuitive and alien. As with any threshold concept, without these particular skills or understanding the student cannot progress. Students need to be assisted with this process. Helping students take responsibility for transitional difficulties is something that Burland and Pitts, for example, consider when they propose the introduction of a first-year 'study skills' module where students are able to reflect and plan sessions based on their particular needs $(2007,289-91)$. Also, it would seem expedient, given Jeff's observations, that students are prepared in time-management skills at secondary school level. In this, Hugh, believes that of the two systems IB and NCEA, IB is better designed to equip students with the required skills.

Hugh - The thing I like about IB - it's very university-like. The workload is high but it's over a long period of time and you have to plan your time well. I can't hold their hands all the way through - they [the students] have to be self-reliant learners. I really like that - it works so well for university. And just like university there are some who leave their work until the last week and go "holy hell- how am I going to get all this work done" - just like university. NCEA is more forgiving in that respect - the projects aren't as big and they can throw them together in a short time; and sometimes they're lucky and 'Achieve'. You just can't do that with IB. For the students coming out of NCEA, it takes a while for them to get their heads out of the NCEA space where it seems that it's pretty easy to negotiate an easy path to avoid all the hard things. 
To readdress the cautionary note sounded in Chapter 1, IB philosophies are only beneficial if the teachings of study and revision strategies support the benefits of delayed assessments. IB can also only be beneficial if the music students are choosing to study under this particular system. Regardless, Hugh's perception that students need to get their 'heads out of the NCEA space' is a particularly damning indictment of the NCEA qualification. It is an indictment shared by Dale Carnegie, professor of engineering at Victoria University. He comments that NCEA students learn to 'game the system'. He states further that: 'we know there's a perception that if you're reasonably intelligent, you can cruise and get an 'Achieved' and that's all you need to do. We have spent a lot of time transitioning in first year courses to break that mind-set' (quoted in Downes 2015, A5). In terms of engineering specifically, he comments: 'I would say NCEA really has done engineering as a university subject quite a disservice' (ibid.). As these and various students' comments we have seen suggest, NCEA does not appear to prepare the student well for the transition between secondary and tertiary study. The students' first year, for example, should not be 'a shock' nor be 'overwhelming'. These findings, specific to the New Zealand pre-tertiary education systems, differ significantly to those of Gavin who, in examining tertiary music students' persistence and withdrawal factors, states that all the students he surveyed found the transition easy due mostly to the students having an instant group or family environment with other performance students. He does concede, however, that due to the majority of students citing one particular aspect of their study as the principal reason they withdrew from their study there is a need for a more detailed understanding of the experiences students encounter. It is of particular interest to this study and in particular reference to the young secondary student described earlier who 'Excelled' at his NCEA performance assessment despite performing poorly that Gavin asks: 'Do students' negative [tertiary] experiences surface as a result of poor preparation and/or an inflated level of confidence prior to entering college?' (2012, 316-17).

It could be argued that the heavily assessment-based education, that Hugh suggests NCEA typifies, leaves little room for students to understand the importance of either the process of acquiring knowledge or indeed the engendering of wider curiosity beyond assessment criteria. In this respect and to provide just one example, comments from a 100-level introductory opera course student are interesting as they reveal the 
implications of what an assessment-based 'head space' can mean at tertiary level. Some weeks after this opera course had finished I asked this student about his final result. He confirmed that he had passed the opera course, but commented that he had managed to do so without watching, in its entirety, any of the required opera viewings. He added gleefully, 'I’ve still never seen a whole opera!'

Freire comments on this absence of 'curiosity' and his observations bring together this idea as it relates to the problematic division of theory and practice as discussed in the previous chapter.

Curiosity about the object of knowledge and the willingness and openness to engage theoretical readings and discussions is fundamental. However, I am not suggesting an over-celebration of theory. We must not negate practice for the sake of theory. To do so would reduce theory to a pure verbalism or intellectualism. By the same token, to negate theory for the sake of practice, as in the use of dialogue as conversation, is to run the risk of losing oneself in the disconnectedness of practice. It is for this reason that I never advocate either a theoretic elitism or a practice ungrounded in theory, but the unity between theory and practice. In order to achieve this unity, one must have an epistemological curiosity.

(Freire. 2005, 19)

\section{Institutional Responsibilities}

The opera student's concerning approach, described above, demonstrates that learning has become tailored to assessments and finite in its enquiry and needs to be considered alongside statistics and student observations previously presented concerning what levels of knowledge students feel they 'need' to acquire and what knowledge it is that they consider now, and in the future, to be relevant. It is a learning approach that demonstrates that the benefits of flexibility in our pretertiary educational systems can be subsumed through other factors; for example, the aforementioned curriculum that is heavily weighted with continual assessments. When considering aspects of variable delivery of music curricula across New Zealand secondary schools - something developed further in Chapter 3 - together 
with the assumption that this is unlikely to change in the short term, it is compelling that bridging knowledge gaps must begin with assessing students' strengths and weaknesses in their 'make or break' year. In so doing, tertiary institutions may then respond to pre-liminal variations without, for example, compounding troublesome knowledge with further troublesome language.

Bridging knowledge gaps is about making troublesome knowledge accessible. Jeff, who has had some experience in tutoring first year students in music theory, makes an observation about what he considers to be institutional responsibilities in this regard.

Jeff - Useful information needs to be more attainable to the students. There are a lot of students not understanding course material, [they're] going to lectures and still not understanding and some of these students have been good at seeking help but they don't understand because it is not being taught in a way that is accessible to the students at all. It's not that it needs to be spoon-fed it's that it needs an adaptive approach to teaching.

Accessibility is the central issue here. If students have never experienced the integration of musicianship elements, if they have had theory 'nailed in their heads' and essentially removed from their performing repertoire, for example, then what they are potentially confronted with at university is inaccessible material presented with ever-increasing complexity. It is difficult for them to even conceive of an 'underlying game' (Land et al. 2006, 197 my emphasis). To make matters worse, lecturers do not always understand from their own knowledge levels that what they are teaching is 'utterly foreign and utterly random. They don't understand how the student can't understand it' $(2006,197)$. The student's earlier comments about a paper that 'existed in its own little vacuum' needs to be considered when thinking of curriculum design in light of these 'utterly foreign' threshold concepts. In reference to Land et al.'s list of institutional considerations (2006, 198-204), getting rid of 'congested curriculum in favour of one that focuses on useful mastery' is particularly relevant in this context. 


\section{Discussion}

In this chapter, I have described the troublesome aspects of threshold concepts and contextualised these in terms of tertiary students' experiences when entering their 'make or break' year. Issues of identity raised in the opening chapter are re-visited in this context. It is possible to observe how the complexities of threshold concepts are compounded by these identity perceptions, by variable curriculum delivery at the secondary-school level and by the effects of limited communication between the secondary and tertiary sectors. Ultimately, the research suggests learning that has been tailored to assessments and thus potentially devoid of wider enquiry compromises students' approach to tertiary study.

Students have talked about their perceptions of their own preparation and threshold concepts are conceptually broadened to consider wider transitional concerns including aspects such as time-management. A discussion of institutional responsibilities highlight the need for careful balancing of course design that is flexible yet engenders useful mastery. In terms of bridging knowledge gaps and making threshold concepts accessible, it is clear that what happens for the students in their first year of tertiary study is crucial.

With reference to institutional responsibilities and with the dual purpose of concluding this chapter and heralding discussions raised in the next, I consider the following paradigms vital. They are based on the premise that inert and ritualised knowledge can be potentially troublesome, counter-intuitive and alien (Cousin 2006, Land et al. 2006). Educators, to reiterate, need to confirm the experiences of students who are 'silenced by the dominant culture of schooling that generally represents and legitimises the privileged voices of the white middle and upper classes' (Giroux 1986, 64-5). It is essential also that institutions 'consider the forms of active student engagement that will bring about transformative understandings, that provide familiar learning examples that can be applied in new situations, and connected to student's lives' (Land et al. 2006). Essentially, 'grasping a threshold concept is never exclusively to do with its inherent complexity ... as learners will always be culturally positioned' (Cousin 2006, 137). 


\section{CHAPTER THREE}

\section{The Vernacular - Transitional Realities}

\section{Introduction}

Giroux challenges educators to question the ideology at work when students are tested in a language they do not understand. In this, he has more broadly addressed implications of Meyer and Land's troublesome language claiming that: 'Language practices can be used to actively silence some students' (Giroux 1986, 51). Bourdieu and Jean-Claude Passeron also comment specifically on the exclusiveness of language as it relates to class and in reference to what they term 'educational mortality':

Language is not simply an instrument of communication: It also provides, together with a richer or poorer vocabulary, a more or less complex system of categories, so that the capacity to decipher and manipulate complex structures, whether logical or aesthetic, depends partly on the complexity of the language transmitted by the family. It follows logically that the educational mortality rate can only increase as one moves towards the classes most distant from scholarly language ...

$(1977,73)$.

More simply put, ironically, this means that complex scholarly language is discriminating. In this context Bourdieu and Passeron argue that language discriminates by class, but equally, language can discriminate culturally.

In this chapter I focus on a New Zealand context and address circumstances and educational models that can be culturally discriminating. It is necessary, I believe, for educators in New Zealand to have an intimate knowledge of our own systems, our cultures, our communities and thus an awareness and mindfulness of our unique cultural landscape. The alternative is to subscribe to colonial educational models that ultimately determine the cultural capital required for entry to university music programmes (Bradley 2012, 414). This chapter, which brings together the epistemological frameworks and expands on issues addressed in the previous chapters, is principally 
devoted to 'Ata' the second and more extensive of this project's two case studies. Ata's lived experiences reveal significant hurdles certain students face as they transition through to their tertiary music studies. It is through Ata that I advance a perspective that insists there is an obligation for tertiary systems to more effectively accommodate the needs of New Zealand students - students who have grown up in a New Zealand sociocultural environment and have had their academic preparation in a New Zealand secondary school.

\section{Case Study - Ata}

Ata was Dux of Music at her secondary school, where she gained all Excellence credits for her NCEA performances. An original choral composition won her a prestigious New Zealand competition and she successfully auditioned for the NZSSC for two consecutive seasons before beginning her music degree majoring in vocal performance. Ata is described by her singing tutor and mentor as possessing exceptional and rich vocal qualities. 'That voice', Jane insists, 'is one in a million, and not only that, [Ata] has an amazing connection to the audience - you can't really teach someone that'. This and the previous accolades, however, belie the realities of Ata's transition to and journey through her tertiary music study.

In her secondary-school years, Ata attended a decile-three college in South Auckland. We talked at length about her experiences there: the peer pressures, her community environment and the resulting transitional challenges:

Ata - Being in a South Auckland school no one wanted to do music, especially - it's all sports. In my fifth form year I was quite bad and rebellious - running away, that sort of thing. Kids who are brought up in that South Auckland environment, they see what's going on in the news and the media and they succumb to that stereotype that South Auckland is bad. I think [kids] put themselves in that box, like that's what we have to live up to - Maori are always getting into trouble; Pacific Islanders are always stealing and beating up people. So, we've put ourselves in that category. That's what the mentality of that school was like. Yeah, in their [the school's] defence, I wasn't the easiest child to teach particularly in 
my fourth and fifth form years. So my principal just said to me "here's the deal, you're not going to waste your life. You either get into the choir, because I know you can sing, or you leave the school". He said, because he cared about me and wanted the best for me, "you either join the choir or get out of the school". He showed me, "these will be your paths if you leave or if you stay". So I thought about it in fifth form and I decided I would join the choir and I think that was definitely the life changer. You know, it sounds quite cliché, but I definitely think that is what changed it because I had sung here and there especially being Maori, you know you sing your whole life, funerals, weddings, everywhere.

L.W. - So, when you started to focus on your music and get things a bit more on track, was there much pull from your friends to keep playing up?

Ata - Yep, like, I started getting bullied. This was like the sixth form so ridiculous! If you were a music student in a South Auckland school you were a geek - that's what you were classed as.

As Ata continues to talk about her music study it is possible to view the same complexities and tensions discussed in the previous chapter between more 'vertical' educational models and those, 'horizontal' that support approachable and flexible curricula.

Ata - So, I joined the choir and then I just had this passion and I started to develop my musical ability. I did my Royal Schools [ABRSM] theory tests and that took a while you know...

L.W. - So did you do that qualification in class or elsewhere?

Ata - That was our end of year exam.

L.W. - So for NCEA, basically, you did the ABRSM Grade 5 theory exam - did you work from a book?

Ata - Yeah, so we worked from the Royal Schools book and I just scraped through like, I was one mark off fail. We had our curriculum 
that we had to be taught, I mean like theory and musical history - I didn't know anything about musical history.

L.W. - Did you write essays or do music history papers for NCEA credits?

Ata - I don't think I ever wrote an essay at high school. Like, I sort of know how to write one now, but I have to get help from Student Services. I have no idea; I don't know the layout of it. My grammar and spelling is horrible. But I know that I just have no idea. The one music history paper that I can remember [at school] was about Bob Marley. Of course being in that environment we all love reggae, like I don't really listen to classical music.

L.W. But that's fine; I see no problem with studying music that's relevant to you...

Ata - Me neither - and it makes the kids strive to do it. They found, I think, the teachers that came into our school, that you can't just go into the school and demand respect - you have to earn it. They were the teachers that stayed around the longest; they're still there now.

L.W. - What do you think the key was to earning your respect?

Ata - I think teaching the kids how to be taught instead of trying to stick to the mainstream teaching, because I can see it doesn't work, especially in our college.

What Ata is trying to communicate here is insightful; her comments about students' interest in their own musical culture and the need to depart from traditional education models or 'mainstream teaching' get to the heart of what is needed in terms of meaningful connection to students' realities and abilities and speak to the importance of finding ways of making learning approachable and relevant. In this sense, making connections is largely about bridging the gap between two musical worlds - that which concerns the musical culture of the students outside school and the musical culture of the classroom (Green 2005, 28). In terms of knowledge acquisition, however, there are institutional considerations that go beyond the need to merely 
embrace students' preferences and expectations. McPhail explains the need to nurture students' interests with a mixed pedagogical approach that will in the long run expand their conceptual knowledge. If we look at his approach through the conceptual lens of Keith Swanwick's 'classification and framing' (1988), McPhail supports weaker framing in terms of teacher-pupil relationships but strong framing with regard to evaluative criteria and with content selection that still endeavours to engender student motivation and ownership (McPhail 2013). If this strong framing aspect is absent, he explains, the students risk remaining 'within their own realm of experience' (2013, 120). In this regard, Ata describes a classroom where the transformative possibilities provided by the guidance inherent in stronger framing are largely absent and, as McPhail describes it, where the progressive versus traditional teaching-approach dichotomies remain unresolved $(2013,122)$.

Ata - In my seventh form music class there was two of us in a population of fifteen hundred - so just two of us. The class would just get smaller and smaller the older we got. We were kind of just left to our own - we didn't really have our teacher there, he was just, like pop in and out. So, we were given choices as to what papers we actually wanted to do for credits. We weren't told what to do; they just gave it to us and said, "you choose, do what you want". We didn't have any deadlines, it was just "hand it in when you've finished", which was always like end of year even though it was due in April or something like that. It was quite easy credits if you had talent. The theory we took was very basic, like the kind that should be taught in Intermediate. ${ }^{28}$ That was how easy it was.

L.W. - Did you like that theory though?

Ata - Yeah.

L.W. - Because it was manageable and accessible?

Ata - Yeah, like that's what I thought I was getting into when I came here [university].

${ }^{28}$ Intermediate covers the two years of schooling that precedes high school (i.e. Years 7 and 8). 
My interpretation of this is not that Ata thought that theory would be at intermediateschool level at university but rather that theory would be 'manageable and accessible' - something that was not the reality for her. Ata went on to explain that she had not accumulated any NCEA credits at any level until she reached her seventh form year (Y13).

Ata - The academic side never really got anywhere with me. Like, throughout my music studies at high school - it was all choir, choir, choir. So, like, I think in seventh form at about term two I was like, "I think I am going to do this, go to university for music". So, I sat down with the careers advisor and she was like, "you don't have any NCEA, you need this, this, and this". I can definitely see that the academic side of learning was my fault because I never wanted to be in class, like I didn't want to do the work. I hated English; I hated maths, science, and social studies. Hated it all. So I just never went. But, I always went to music - that was the one thing that I would always go to and you can see that in my grades.

It was so bad, in my seventh form at about term two I was like, "I think I am going to do this, go to university for music". So, in terms three and four I smashed out NCEA L1, smashed out NCEA L2. So, I was doing Levels one, two, and three in two terms. Well, I had enough credits - I think I was about fourteen credits short for NCEA L1, twenty credits short for L2, then music scraped me through for NCEA Level 3. So, I definitely had to work hard to be able to get University Entrance. ${ }^{29} \mathrm{I}$ did dance, drama, music, NCEA Level 3, music by correspondence - I did music twice and then I did classical studies. And I think I got like six credits in classical studies, twelve in dance, really low credits. I hated dance, but it was easy credits.

In a discussion about this huge workload in her seventh form year, she said:

Ata - Yep, I think my biggest achievement was that I ended up getting Dux of music. Yeah, like a Dux is a Dux to me - even if it's musical.

\footnotetext{
${ }^{29}$ See University Entrance details and requirements in 'Terminology' pg. viii.
} 
Ata's urgent push for retrospective NCEA credits and the wish to study music at university was motivated, principally, by an opportunity to audition for the NZSSC. This was a school initiative.

Ata - Yeah, all the choir was kind-of forced to go and I can see now that they were just trying to create a wider vision for us, showing us that there was more to life than just being at school doing nothing. So I got in and another guy and so then I just started realising that singing - I think - is what I wanted to do. At the time I was playing softball with the New Zealand youth team, but I ended up breaking my leg so I couldn't take the scholarship that I got to go to Missouri to play softball for a year. So, I chose the choir instead and I'm definitely glad I did. I wouldn't have chosen it any other way. So, that was one of the things as well, do I choose sports or do I choose singing? What's going to take me further?

Before that [involvement with the NZSSC] I had no idea that music was actually a profession, I just thought choirs were here and there. I didn't even know what an aria or an opera was and the only classical thing that I knew was Mozart and that is it. I didn't know anything about sopranos and I was like, "you can make a career out of classical singing"!? And then I think that's really where my musical career took off. The choir went to the 'Melody of Music' festival in Argentina; I had never been on a plane before. The school and the community got the money together and paid for it because we couldn't afford it and also it had never kind of happened in our school before.

Ata adds that the NZSSC experience significantly extended her and she makes the comment, for example, that the sight-reading requirement was very different to the rote learning they did at college:

Ata - I didn't know how to read music. We had always been taught by ear and even now if you played me a song once I could sing it back to you, but if you gave me a piece of music and asked me to sing it, I would have no idea. Like, learning my music and stuff, it would take me a whole year just to learn a song. 
As Ata and I talked more about her transition to tertiary study and the implications of her secondary school preparation, her admission that 'even now' she had difficulty sight-reading made it clear how hard it must be for her to keep up with the demands of the extensive repertoire required at university. About her first experiences at university, she said:

Ata - I started to realise this is a whole other level compared to high school. I definitely feel that I am the outcome of what school has done. I think my perception of university was that it was going to be about the same as high school, [but] then I struggled because the other kids might have come from decile-ten schools say, and they know all of this stuff because their musical schooling has been top-notch.

If I think about it all of my NCEA credits to get University Entrance were for performance. ${ }^{30}$ So when I made the transition from seventh form to first year [university], I was going from being an 'Excellent' performer like, still being an excellent performer here at university, but [here] my performance grades are all As and my academic are like $\mathrm{C}$ minus and D. So, I was actually quite overwhelmed in my first trimester where I was ready to throw it all in because I failed everything. My first year, I failed the whole thing apart from one paper.

Any university's cultural environment, as Giroux reminds us, generally legitimises the privileged voices of the white middle classes, which I believe in this instance served to compound the effects of Ata's poor academic preparation. Listening to what Ata has to say about her own cultural environment is perhaps the key to understanding some of the complexities surrounding her often-alienating experiences at university. She begins with describing the difficulties she had in asking for assistance with her academic work.

Ata - Getting the courage to ask for help would definitely be one of my hardest things in my uni life, because I think that culturally you don't ask for help, that is the truth. We've always been told if you have got a problem you just harden up. I definitely think that in first and second year I really struggled with asking for help. The first time I walked into

\footnotetext{
${ }^{30}$ While this, and her previous summation of credits is not an extensive list, she makes no real mention of the literacy and numeracy credits required for university Entrance.
} 
Student Services I just burst into tears and I felt like I had failed because I had to ask for help.

Going to Student Learning Services (SLS) for help was not something Ata did of her own volition. Her singing tutor describes the process:

Jane - It took me ages to convince her to go to SLS. I think she finally went at the end of her second year. I finally got Ata and [her SLS person] together and it has been fantastic. They befriended her and we got her reporting back. Ata arrived [at university] with no self-esteem whatsoever ... and to get that out of her mind took me about a year $-\mathrm{a}$ year to say: "you're worth it".

Ata goes on to communicate how she perceives the disparate nature of two worlds her world and the university's. As she describes the tensions with regard to her own positioning in these different worlds, it is particularly interesting to note her conflicting voices - the apprehensive voice that reflects disenfranchisement and the culturally assertive voice.

Ata - I think one thing that really shocked me when I came here was the cultural difference. Especially being brought up in South Auckland and surrounded very much by Maori and Pacific Island culture - coming here and just seeing the difference. There was like one European girl in my whole school and that's it. I think there's a huge difference between my world and the opera world - the classical opera community - it's so... [pause] not me. I don't have a hidden agenda about anything. The opera scene is very 'cliquey' and there's kind of like little me, as an outsider, over here, trying to get in. I am not going to change who I am to make someone else happy, I am doing this for me, they are not living my life. I am happy to be by myself and know this is who I am really - you can't change me.

Throughout the years there has definitely been times I have almost fallen into that trap and I just realise where I come from. This is like sometimes where I don't agree with the opera scene, you don't get to see your family and I am very much family orientated. They are my priority and I 
think, like a lot of my friends they don't understand that. It's okay, but they are all, like “oh it's okay I haven't seen my family for years or I haven't seen my sister for years", but I can't go a month without seeing my family. So, I think that's a huge difference between my world and the opera world - it's like "you have to be this, you have to be that".

The finance was really tough, most of my friends - their parents are paying their rent or board and giving them money for food. My parents haven't given me anything since I started. They have worked really hard to get where they are now and I am not going to ask them for money. I have worked at Farmers, Harvey Normans ... it got to the point where I was working full time and studying at nights and not sleeping. That was the reality; then I got really sick, but I needed to do it to survive.

When Ata did get sick the consequences of her reluctance to seek help were particularly serious. Jane explains:

Jane - One year Ata was very sick. I find it hard to comprehend - was it being chased and followed up? It was found eventually that a GP hadn't done a particular test that should have been done and she ended up in hospital nearly dead with one collapsed lung. So, there's a whole range of issues - I would say go and see [someone] and she would say, "no I'm fine". So convincing her that she's worth the effort; that the voice is worth the effort.... These kids from low-decile schools, there's a lot of effort involved in saying "you are worth it".

Family commitments and obligations have also impacted on Ata's attendance at university. She cites an instance when, due to some concerns at home, her mother booked a flight to Auckland for her and told her, as the oldest, that she needed to be on the plane at the end of the week. There was no prior notice given and no real opportunity for Ata to organise her university commitments. But, most importantly, as Ata stressed, there was no possibility of saying "no" to her mother. Larger whānau ${ }^{31}$ commitments such as funerals are similarly problematic.

\footnotetext{
${ }^{31}$ Whānau - extended family or family group
} 
Ata - One time they [the University] were going to fail me on my attendance because I was actually away at my uncle's funeral. ${ }^{32}$ I was away for two weeks. I was angry because that's how long it takes. Like, it was all over TV! That's what I had to fight for because I had a C plus, but because I was away they were going to fail me.

The specifics of this are not necessarily important here as I am only able present Ata's understanding of the event. It is possible, for example, that Ata would have left for the tangi $^{33}$, as would be her whanau's expectations, with little thought about what the repercussions might be for her at university. What is of consequence and what in this particular instance appears to have prevailed in the long run is the importance of institutional understanding and accommodation of New Zealand students and their cultural environments.

Additional cultural differences can make the adjustment to university life difficult for Pacifica students. For example, it has been my experience that Maori and Pacific Island students are very reluctant to contribute to class discussions. Ata gives an example:

Ata - [In class], if the lecturer will ask me a question I just won't answer because, in my head it's wrong - "don't say anything because it's wrong”. In front of a full lecture class, everyone gives their opinions and I just won't say anything. Sometimes it's because I feel I'm not as academic as them, but there's like this little voice that is in my head says, "no - don't say that because you are wrong".

The academic implications of Ata's pre-tertiary preparation and engagement that are compounded by cultural disparities has meant she has spent five years completing a degree that normally takes three. She has failed numerous papers including some first and second year theory papers two or three times. In a discussion about one of the two papers she needed to repeat in order to finally complete her degree, she describes, I believe, the exact nature of troublesome language and confirms that transitional gaps exist beyond those of the school and university to include gaps between students and

\footnotetext{
${ }^{32}$ A well known public figure.

${ }^{33}$ A tangi (funeral) for Maori, particularly in this instance where the deceased is a man of such stature, involves a large community gathering. It is expected that the extended whanau will attend often traveling great distances to the deceased's marae. Various proceedings will take place over a number of days or weeks until the deceased has been farewelled in the customary manner.
} 
academics (Parker 2003, 64) and the previously described dissemination of utterly foreign and random concepts.

Yeah, I [originally] quit half way through because I got there and I thought "I've just got no idea what you're talking about - just absolutely no idea". Lecturers have given me this and that, but it hasn't really helped. I say to them "I need to be taught in a way that I can understand it. If you can break it down for me". Sometimes I feel like I just get put in the too-hard basket a lot of the time.

Reflecting on what she had managed to achieve, I asked Ata what courses she felt had been valuable and she, like many other students surveyed, identified the courses that informed her performance repertoire.

Ata - I love facts about stuff and I love knowing the origins of where things are coming from - learning about these different people and how it actually affects what I sing about and what part they had to play in all of this.

L.W. And what courses did you like the most?

Ata - That's a hard one - I don't even think I really liked any of them.

L.W. - Why is that?

Ata - The biggest thing for me personally is I find it so hard to keep up with the work. The level that they teach, the academic language, I don't understand. So, what I actually do in my lectures is: instead of taking notes in class, I have actually come up with a way of where I just record the whole lecture and I sit there and write down words that I don't understand. And that is how I need to learn it because I just don't understand.

While in another context yet directly relevant in terms of accessibility, Emma, formerly quoted in Chapter 1 in her role as a NCEA assessor, makes a similar and salient point about troublesome academic language. 
Emma - I have had some of my Asian university students come to me for help with essay topics saying they don't understand it and frequently $I$ don't know what they [the lecturers at university] are talking about either. I find that the language that's included - I have to translate it back to myself then give them the broad strands that the topic is asking to be considered. So, for these students, there are two levels of language to negotiate, the English and then the academic language on top.

With only one summer paper now to complete, Ata is nearing the end of her degree. She has yet to experience the realities of her large student loan that has been the result of frequent and multiple course failure and the resultant extended study. She says about her time at university:

Ata - I am definitely not a quitter; I will stay as long as it takes. Even though I feel like giving up sometimes I won't. Because, I just try and remember why I started and why I am here. The year before last was almost my breaking point because I wasn't enjoying it anymore and I became constantly sick and depressed. I said to [Jane] "This isn't fun anymore, I feel like singing should be fun, this is what changed my life and now it's not fun". But then later I realised that I came here because I can sing and I'm passionate about it and no one is going to step in the way of it. I love it and hope to teach back at my school and help kids that are like me, that just need someone to believe in them. It's definitely been a tough road, but I am not giving up until I get that piece of paper that says I have a degree. [She laughs at this point and says]: I try to see the best of things but it's been really, really hard.

\section{Discussion}

This chapter has been about the challenges associated with one student's preparation, transition, and academic journey. In relaying Ata's experiences, I have two principal motivations. The first, as stated previously, is to provide rich description and detail in a case study that fuses the theory and the practice, and thus enables clearer 
understandings of the transitional issues for performance students in New Zealand particularly those whose musical potential may far exceed their academic preparation. The second and related motivation is to revisit the 'before' in order to discuss the pretertiary and transitionary experiences addressed in the previous chapters and to put them in the context of the 'after'; that is, through the experiences of someone whose pre-tertiary environment, preparation, and engagement have meant the curriculum requirements of her music degree have provided significant hurdles - hurdles that applied unilaterally are likely unnecessary and that, for someone less tenacious, could be insurmountable.

The broader transitional concerns highlighted in this case study are numerous. They include considerations of pre-tertiary cultural environments, the importance of sociocultural relevancy in pedagogical practice, transitional hurdles related to expectations of tertiary study, and the need for accessible, manageable, and meaningful connections between secondary and tertiary levels of knowledge. The more specific considerations that are immediately confronting are, for example, the realities of lower decile school environments where the peer pressures, community culture, and levels of student engagement hinder academic growth and performance. Further compounding these concerns are matters related to the way in which NCEA music curriculum and assessments are tailored by different schools, while concerning in its own right, can also result in students' false and often heightened expectations of tertiary study.

In reading through Ata's transcript a simple assumption could be that her secondary school preparation, compounded by her late engagement with it, has resulted in her being particularly underprepared for the demands of music study at the tertiary level. Her need to repeat numerous courses through her five-year journey is perhaps testament to this. Turning this assumption on its head, however, is to propose how both the secondary and tertiary educational systems and curricula have failed to accommodate the needs of students like Ata. As a student in a New Zealand school studying under educational systems conceived in New Zealand for New Zealand students, Ata is neither an anomaly nor exceptional. In this regard, there are a number of realities that cannot be ignored. The first of these is that Ata has enormous potential that in Jane's opinion could result in her succeeding at the very highest levels - indeed she 'could be the next Kiri Te Kanawa if she wanted to'. A second reality is that Ata 
was both encouraged and accepted into a university music degree programme based on this potential and, at least on paper, sufficient academic results. It is not acceptable to assume 'that admission to a music school is generally awarded specifically to a high level of skill in a narrowly specified area' (Kingsbury 1988, 4) and then to not provide the kind of assistance necessary to assure a successful transition. A third reality is that there has been enormous time invested by the University to assist Ata, but ultimately, it has been her particular tenacity that has made her imminent graduation a possibility where many other students in similar circumstances would have failed.

There is no doubt also that the series of events beginning first with her principal outlining her potential paths, her acceptance into the NZSSC and finally her degree level education have meant that Ata has considerably more options for her future than would otherwise have been possible. Despite this, and in light of her very considerable student loan, questions remain about whether certain hurdles that Ata has been required to negotiate in the process of earning her degree have been beneficial or necessary. One might ask: is the fact that Ata has the potential to succeed at the highest levels yet failed at almost every turn the very definition of systematic failure?

Institutions need to question critically why students are asked to acquire certain skills and knowledge. Giroux, for example, discusses the nature and complexity of how knowledge is measured, administered, and ultimately received. He comments on this predetermined and hierarchically arranged nature of imparting specific forms of knowledge. He asks three questions: 'How is such knowledge chosen? Why might students be interested in acquiring such knowledge and, most importantly, whose interests does this knowledge actually represent'? Giroux suggests ultimately that it is often 'matters of control, management, and efficiencies that lead to pedagogical practices that ignore the interests and needs of the student population' $(1986,50)$. Ken Robinson agrees and says that our education systems, typically, have a culture of standardisation whereas they should be creatively individualising teaching and learning practices (2013). With specific reference to music schools, Tregear has asserted that if we are to 'reaffirm and recommit (both financially and culturally) to higher education in music into the future there is an urgent need to think again ... not just about how, but also why, we teach music on campus'. He is also concerned about the uncritical pitch made to students and suggests that university music departments need to reassert 
that technical accomplishment alone is not enough of a foundation, let alone a justification, for a career in music. 'We have an urgent need instead', he says, 'to produce graduates who have an empowered sense of agency and responsibility for the musical culture that now surrounds us. To do that, we need urgently to reassess both what we teach and how' $(2014,25)$. For institutions, this means urgently reassessing the curriculum; as Fred Maus has observed, for example, it is one thing to imagine expanding the curriculum to include new areas of knowledge and quite another to imagine a different type of student who might 'lack many of the skills of a good classically-orientated major' $(2004,63)$. 


\section{SUMMARY and CONCLUSIONS}

This thesis has explored, through the theme of language, the transition between secondary and tertiary study for music students majoring in performance in New Zealand. There are questions raised in the literature that I have endeavoured to address through an ethnographic and interpretive approach. Questions, for example, that ask: Do we have sufficient knowledge of pre-tertiary environments in New Zealand? Are students' levels of knowledge assumed? Are students' diverse needs accommodated? To what extent are students' expectations and identity constructions influencing their approaches and attitudes to learning at tertiary level?

In Chapter 1, I focused on students' preparation through their secondary schooling and introduced 'Liz' the first of two case studies. I discussed aspects of these pre-tertiary systems, for example, the compartmentalisation of musicianship components, which I suggest result in learning behaviours and student subjectivities that have significant impact on how they will engage with their tertiary music studies. I also suggested that the 'binary flip switch of disengagement', something that is inherently linked to aspects of identity formation, is a formidable hurdle for tertiary educationalists. In this regard, the robustness of a widely conceived music degree is significantly undermined if the students' perceptions of their own musical identities result in a determined focus that precludes investment in it. The same issues of identity and disengagement are also a reason to question any hypothesised transferability between performance and academic confidence.

In the second chapter I introduced aspects threshold concepts, namely troublesome language, troublesome knowledge, and liminality. I described how these challenges are compounded by educational practices in New Zealand in terms of how students are prepared and with reference to the importance of balancing curricula that is flexible yet comprehensive. I discussed the very real possibility of a resultant 'NCEA head-space' where it was suggested that students' attitudes to learning are limited and their preparation for tertiary study is compromised by curriculum that is overly assessmentbased and thus weighted toward product versus process learning and teaching. Student language shows perceptions about their lack of preparedness for tertiary study and thus, the importance of what students encounter in the first 'make or break' year was made 
explicit. In terms of the students' first year I also conceptually broadened the scope of threshold concepts to include further challenges, for example time management, that are part of the huge personal adjustments students make at this stage of their lives. I argue that if students do not manage these particular challenges, as with any other threshold concept, they cannot successfully transition or progress through their tertiary studies.

Chapter 3 focused in on New Zealand and more specifically the realities of challenges faced by one particular performance student, Ata. On the premise that educational systems and institutions operating in New Zealand have a responsibility to students in New Zealand - to accommodate the lived realities that they face in their communities and pre-tertiary environments - I raised issues related to lower-decile schools in communities where pressures and cultures can hinder academic growth and performance. I suggested that certain curriculum choices and requirements conceived in times, countries, and cultures far removed from New Zealand result in hurdles for these students that are arguably unnecessary and often insurmountable. In this respect, the student is often problemetised and bears the weight of course failure. Educational initiatives around the world in recent years have meant that there are more teaching strategies that provide for alternative methodologies and choices for students, including learning environments that are self-directed and relevant to their own lives. However, in a New Zealand context, at least, we might challenge Green's assertion that there is 'evidence of these changes leading to increased motivation and more diverse opportunities for children from different classes and cultures to take part and succeed from the school to the higher educational sphere' $(2012,212)$.

I am acutely aware that in a study of this size and scope it is worth being cautious about drawing realisable conclusions; my ethnographic approach has been exploratory in nature and my purpose has been to create a more comprehensive understanding of the issues. I do draw attention, however, to the transitional issues facing music students in New Zealand and proactively suggest, at least, some cause and effect. As Louis Cohen et al. remind us, researchers and their research are neither neutral nor innocent (2011, 243). As ethnographers we need to state our positions and as education researchers, in our attempts to fuse theory and practice, it is perhaps incumbent upon us to do more than reflect on the issues. 
It was not my original intention in this study to focus so extensively on NCEA. However, as an emergent theme, discussions resulting from concurrent research together with the educators' and the students' perspectives points to this particular system being, if not responsible then at least, a significant contributor to poor preparation and significant homogeneity of learning subjectivities across the student cohort. Any benefits in preparation through the more robust NCEA components, namely Music Works or L3 Harmony, are circumvented by the way these subjects and others are tailored by individual schools, which allow students to negotiate the curriculum by, for example, opting out of aural components or by attaining 'easy' performance credits. Tertiary institutions in New Zealand are unable to assume a level of musical understanding or achievement of their first-year students when there is such variable curriculum delivery at the secondary level. Qualifications only tell part of the story. In this regard, I see the alternative use of the ABRSM or Trinity Grade 5 standard as an entry pre-requisite as problematic for a number of reasons. Firstly, as with any qualification there are significant knowledge gaps between those students who may have a firm grasp of the concepts at this level and those, who like Ata, scrape through with minimal understanding that suggests they are, in all likelihood, stuck in liminal spaces. Secondly, if we take heed of what the students are saying about firstyear university theory being at a much higher level than they have encountered before then we must assume that Grade 5 is not, in reality, sufficient preparation - at least in respect of the pre-determined challenges as they exist currently. Lastly, and most importantly, tertiary institutions, by relying on this external qualification, are effectively making little or no investment in ensuring that music students are well prepared by our principal pre-tertiary qualifications here in New Zealand.

It is important to ask what knowledge each education sector has of the other and this lack of investment is likely symptomatic of the poor communication between NZQA and secondary and tertiary institutions. Students, for example, need to know what they will encounter and what they are preparing for. Equally, there needs to be greater awareness among tertiary academic staff of the skills that students bring to their first year of study. With the pressures of funding and student numbers being crucial to the very existence of tertiary music schools in New Zealand, there remains a very real responsibility to our 'most important stakeholders'. If performance students are not investing in the broader aspects of musicianship at tertiary level, which this research 
suggests is the case, then it becomes the universities' responsibility to make explicit their expectations and to take an honest approach to both the entry requirements and to the pitch they make to prospective students. If students are to transition successfully and extend their knowledge in the wider aspects of musicianship, it is critical that they are invested in the process from the beginning. There is an urgent need to take practical steps to develop educational practices that mediate differences in pre-tertiary knowledge and in this respect consideration of the range of courses that students first encounter is paramount.

This study scratches only the surface of research possibilities. There is enormous scope and benefits in developing further lines of enquiry regarding the secondary to tertiary transition process for music students. In this, there are also certain findings that are transferable in other subject disciplines. The focal point of this study has been on students' experiences, identities, and perceptions, however, I consider that a focus on institutions, that allows us to pursue the considerable repercussions of transitional difficulties in terms of course design and assessment criteria, to be particularly worthwhile. Further enquiry and strategic planning into the early introduction of more widely conceived musicianship skills, for example, would be beneficial both in terms of successful transitions and for students' future employment trajectories. There is also a wealth of material for an ethnographic study of Ata's experiences alone, for example, that may or may not fall outside considerations of secondary to tertiary transition.

To conclude, I return to aspects of language. Language has been instrumental in both determining performance student subjectivities and revealing perspectives about their transitions from secondary to tertiary music study. Students have used language to define, mediate, and understand. If educators are receptive to this and can imagine for the future a variety of pedagogical approaches that will assist students to transition more successfully then institutional language may well shift from being a language of transmission to one of transformation. 


\section{REFERENCES}

Asmus, Edward P. Jr. 1986. "Student Beliefs About the Causes of Success and Failure in Music: A Study of Achievement Motivation." Journal of Research in Music Education 34: 262-278.

Ausubel, David Paul. 1968. Educational Psychology: A Cognitive View. New York: Holt, Rinehart and Winston.

Bernstein, B. 2000. Pedagogy, Symbolic Control and Identity (Revised Edition). New York: Rowman \& Littlefield.

Black, Paul, and Dylan Wiliam. 1998. Inside the Black Box: Raising Standards Through Classroom Assessment. London: School of Education, King's College London.

Bourdieu, Pierre 1984. Distinction: A Social Critique of the Judgement of Taste. Cambridge and M.A.: Harvard University Press.

Bourdieu, Pierre, and Jean-Claude Passeron. 1977. Reproduction in Education, Society and Culture. Translated by Tom Bottomore. English ed. London; Beverly Hills: Sage Publications.

Bradley, Deborah. 2012. "Good for What, Good for Whom?: Decolonizing Music Education Philosophies." In The Oxford Handbook of Philosophy in Music Education, edited by Wayne D. Bowman and Ana Lucía Frega, 409-433. Oxford; New York: Oxford University Press.

Burland, Karen, and Stephanie Pitts. 2007. "Becoming a Music Student: Investigating the Skills and Attitudes of Students Beginning a Music Degree." Arts and Humanities in Higher Education 6(3): 289-308.

Burnard, Pamela. 2007. "Telling Half the Story: Making Explicit the Significance of Methods and Methodologies in Music Education Research." Music Education Research 8:2 (Published online): 143-152.

Burt, Rosie, Helen Lancaster, Don Lebler, Gemma Carey, and Matt Hitchcock. 2007. "Shaping the Tertiary Music Curriculum: What we can Learn from Different Contexts." NACTMUS National Conference, Music in Australian Tertiary Institutions - Issues for the 21 st Century, Brisbane.

Carey, Gemma Marion. 2004. "New Understanding of "Relevant" Keyboard Pedagogy in Tertiary Institutions." PhD., School of Cultural and Language Studies, Queensland University of Technology.

Cohen, Louis, Lawrence Manion, and Keith Morrison. 2011. Research Methods in Education. 7th ed. Oxon; New York: Routledge. 
Colwell, Richard J. 1999. "The Future of Assessment." Journal of Aesthetic Education 33(4): 53-75.

Cook, Anthony, and Janet Leckey. 1999. "Do Expectations Meet Reality? A Survey of Changes in First-year Student Opinion." Journal of Further and Higher Education 23(2): 157-171.

Cousin, Glynis. 2006. "Threshold Concepts, Troublesome Knowledge and Emotional Captial." In Overcoming Barriers to Student Understanding: Threshold Concepts and Troublesome Knowledge, edited by Jan H.F. Meyer and Ray Land, 134-147. London and New York: Routledge.

Davies, Peter. 2006. "Threshold Concepts: How do we Recognise Them?" In Overcoming Barriers to Student Understanding: Threshold Concepts and Troublesome Knowledge, edited by Jan H.F. Meyer and Ray Land, 70-84. London and New York: Routledge.

De Graaf, Paul M., and Maarten H. J. Wolbers. 2003. "The Effects of Social Background, Sex, and Ability on the Transition to Tertiary Education." The Netherlands Journal of Social Sciences 39(3): 172-201.

Downes, Siobhan. 2015. "The Reason Why Fewer Students are Getting UE." Dominion Post, Wellington New Zealand. 8.7.2015, A5.

Elliott, David J. 2005. Praxial Music Education: Reflections and Dialogues. Oxford; New York: Oxford University Press.

Ellsworth, Elizabeth. 1989. "Why Doesn't This Feel Empowering? Working Through the Repressive Myths of Critical Pedagogy." Harvard Educational Review 59 (3): 297-324.

Ellsworth, Elizabeth Ann. 1997. Teaching Positions: Difference, Pedagogy, and the Power of Address. New York: Teachers College Press.

Freire, Paulo. 1985. The politics of Education: Culture, Power, and Liberation. Massachusetts: Bergin \& Harvey Publishers.

Freire, Paulo. 2005. Pedagogy of the Opressed. $30^{\text {th }}$ Anniversary Edition, trans. Myra Bergman Ramos. New York; London; Continuum.

https://libcom.org/files/FreirePedagogyoftheOppressed.pdf

Gauldin, Robert, and Mary Wennerstrom. 1989. "Pedagogy." Music Theory Spectrum 11(1): 66-73.

Gavala, Jhanitra R. and Ross Flett. 2005. "Influential Factors Moderating Academic Enjoyment/Motivation and Psychological Well-being for Maori University Students at Massey University. New Zealand." Journal of Psychology 34 (1): 52-57. 
Gavin, Russell B. 2012. "An Exploration of Potential Factors Affecting Student Withdrawal From an Undergraduate Music Education Program." Journal of Research in Music Education 60(3): 310-323.

Geertz, Clifford. 1973. The Interpretation of Cultures. New York: Basic Books Inc.

Giroux, Henry A. 1986. "Radical Pedagogy and the Politics of Student Voice." Interchange 17(1): 48-69.

Green, Lucy. 2005. "The Music Curriculum as Lived Experience: Children's "Natural" Music-Learning Processes." Music Educators Journal 91(4): 27-32.

Green, Lucy. 2012. "Music Education, Cultural Capital, and Social Group Identity." In The Cultural Study of Music: A Critical Introduction, edited by Martin Clayton, Trevor Herbert and Richard Middleton, 206-216. New York; London: Routledge.

Harrison, Carole S. 1990. "Predicting Music Theory Grades: The Relative Efficiency of Academic Ability, Musical Experience, and Musical Aptitude." Journal of Research in Music Education 37: 124-137.

Jorgensen, Estelle R. 1997. In Search of Music Education. Urbana and Chicago: University of Illinois Press.

Kerman, Joseph. 1985. Contemplating Music: Challenges to Musicology. Cambridge, Mass.: Harvard University Press.

Kingsbury, Henry. 1988. Music, Talent, and Performance: A Conservatory Cultural System. Philadelphia: Temple University Press.

Kteily-O'Sullivan, Laila R. 1996. "Freshman Music Students' Identification with Expected Tasks in the Music Theory Class as a Relevant Part of Becoming a Musician." Doctor of Philosophy Doctoral thesis, University of North Texas (9714040).

Land, Ray, Glynis Cousin, Jan H.F. Meyer, and Peter Davies. 2006. "Implications of Threshold Concepts for Course Design and Evaluation." In Overcoming Barriers to Student Understanding: Threshold Concepts and Troublesome Knowledge, edited by Jan H.F. Meyer and Ray Land, 195-206. London and New York: Routledge.

Lebler, Don. 2008. "Popular Music Pedagogy: Peer Learning in Practice." Music Education Research 10(2): 193-213.

Maus, Fred Everett. 2004. "Ethnomusicology, Music Curricula, and the Centrality of Classical Music." College Music Symposium 44: 58-67. 
McCoy, Carol Piatnek. 2011. "The Development of a Keyboard Theory Curriculum Utilizing a Chronological, Comprehensive Approach to Reinforce Theory Skills of First Semester College Music Majors." University of Florida. http://purl.fcla.edu/fcla/etd/UFE0042774.

McPhail, Graham J. 2009. "Searching for Standards in the NCEA: Assessing Musical Performance." Waikato Journal of Education, 14, 15-30.

McPhail, Graham J. 2012a. "Knowledge and the Curriculum: Music as a Case Study in Educational Futures." New Zealand Journal of Educational Studies 47 (1): 3346.

McPhail, Graham. J. 2012b. "From Singular to Over-Crowded Region: Curriculm Change in Senior Secondary School Music in New Zealand." British Journal of Music Education, 29 (3): 317-330.

McPhail, Graham J. 2013. "Mixed Pedagogic Modalities: The Potential for Increased Student Engagement and Success." New Zealand Journal of Educational Studies 48 (1):113-126.

Meyer, Jan H. F., and Ray Land. 2006a. "Threshold Concepts and Troublesome Knowledge: An Introduction." In Overcoming Barriers to Student Understanding: Threshold Concepts and Troublesome Knowledge, edited by Jan H. F. Meyer and Ray Land, 3-18. London and New York: Routledge.

Meyer, Jan H. F., and Ray Land. 2006b. "Threshold Concepts and Troublesome Knowledge: Issues of Liminality." In Overcoming Barriers to Student Understanding: Threshold Concepts and Troublesome Knowledge, edited by Jan H.F. Meyer and Ray Land, 19-32. London and New York: Routledge.

Morrison, Marlene. 2002. "What do we Mean by Educational Research?" In Research Methods in Educational Leadership and Management, edited by M. Coleman and A. Briggs, 13-36. London: Paul Chapman Publishing.

Parker, Jan. 2003. "Access and Transition to Higher Education: A Forum." Arts and Humanities in Higher Education 2 (1), 63-64.

Pitts, Stephanie E. 2004. "Starting a Music Degree at University." In The Music Practitioner, edited by Jane W. Davidson, 215-224. Hants; Burlington: Ashgate Publishing.

Pitts, Stephanie E. 2013. "Would you Credit it?: Navigating the Transitions Between Curricular and Extra-Curricular Learning in University Music Departments." Arts and Humanities in Higher Education 12(2-3): 194-203. Accessed 20/3/2014.

Prosser, Michael, and Keith Trigwell. 1999. Understanding Learning and Teaching: The Experience in Higher Education. Buckingham [England]; Philadelphia, PA: Society for Research into Higher Education \& Open University Press. 
Regelski, Thomas A. 2004. "Social Theory, and Music and Music Education as Praxis." Collected Work: Proceedings of the Third Symposium on a Sociology of Music Education. 3(3): 52.

Renshaw, Peter. 2002. Connecting to Context: Signposts for the Future Direction of Queensland Conservatorium Griffith University. London: Queensland Conservatorium Griffith University.

Rideout, Roger. 2005. "Whose Music?: Music Education \& Cultural Issues." Music Educators Journal 91(4).

Robinson, Ken. 2013. "How to Escape Education's Death Valley." Ted Talks. Accessed 7.7.14.

Sadler, R.D. (1989). "Formative Assessment and the Design of Instructional Systems." Instructional Science 18: 119

Servias, David. 2011. "Towards Confident and Informed Musicianship: A Curricular Synthesis of Theory, Ear Training, and Harmony, Achieved Through the Acquisition of Keyboard Skills." DMA, University of Washington. (3406019).

Small, Christopher. 1996. Music, Society, Education. 3rd ed. Hanover, London: University Press of New England. Original edition, 1977. London: J.Calder.

Spencer, Piers. 1993. "GCSE Music: A Survey of Undergraduate Opinion." British Journal of Music Education 10(2): 73-84.

Swanwick, Keith. 1988. "Music, Mind, and Education." Routledge. http://site.ebrary.com/id/10101114.

Tregear, Peter. 2014. Enlightenment or Entitlement: Rethinking Tertiary Music Education. In Platform Papers: Quarterly Essays on the Performing Arts, edited by Currency House. Sydney.

Watene, Susan. 2006. "A Merging of a Eurocentric Model - Learning Communities with an Indigenous Model - Whakawhanaungatanga." $9^{\text {th }}$ Pacific Rim First Year in Higher Education Conference, Engaging Students. Griffith University: Australia.

Wong, Deborah Anne. 2004. Speak it Louder: Asian Americans Making Music. New York: Routledge. 


\title{
Appendix I
}

\section{Talking About Transition \\ An Exploration of the Secondary to Tertiary Transition Process for Music Students in a New Zealand Context}

Master's Thesis: Researcher - Lynne Wenden

[Email address]

\begin{abstract}
Music Student Survey ${ }^{34}$
This confidential survey asks how you came to tertiary music study and about the journey you made to get there. If you agree, further down the line, to participate in a follow-up interview, I would then ask you to expand on the details you have given here and additionally I may ask about your tertiary study experiences. I am interested in obtaining feedback from as diverse a range of students as possible. More importantly, I want to learn from your personal experiences in order to gain a student perspective.
\end{abstract}

1. Name:

Age:

Email:

2. In which city and country did you do the majority of your pre-tertiary music study?

(City) (Country)

3. What is your music degree major? (E.g. Performance-violin/voice* / Music Studies / Composition / Jazz / Sonic Arts etc.)

*Performance students please be specific about your voice or instrument/s.

4. What theory qualification did you submit to gain admission into your music degree (e.g. Transition theory course / Grade 5 theory / Theory Placement Test / Other).

5. What is the highest formal pre-tertiary theory level you have attained? (e.g. Grade 6 ABRSM/Trinity College/AMEB / or 'no exams but completed theory book 4 'Dulcie Holland series')

\footnotetext{
${ }^{34}$ N.B. For reasons of expediency/space/word count, the numbers of text lines on this survey, and others in these appendices, do not accurately represent those left for students' answers on the original form.
} 
6. Please detail where you gained your music skills (both practical and theoretical). (e.g. Taught by private instrumental teacher / through NCEA / Own study at home / or combination of these). Please be specific if you did some study under your private teacher (to what level?) and whether you continued this study at school or elsewhere.

7a. How many music teachers have you had to date? (Privately) (In secondary School)

7b. Did you have the same teacher for music theory and practical or did you go to someone specifically for theory tuition?

8. Over how many years / months (approximately) have you studied music theory? Please detail if you have studied theory continuously, perhaps in conjunction with your instrument study or whether you have completed short courses as it became necessary - for example to pass an exam or entry test or similar. Please detail also if you have only studied music theory at secondary school for NCEA or similar.

9. What musical activities at secondary level/teenage years have you pursued beyond private lessons or school instruction? (E.g. Youth orchestra, secondary school jazz and, youth/church choir, YMP, own band or individual performance opportunities). List all if possible.

10. (N.B. Question 10a and 10b are for all students other than piano-performance / harpsichord / organ majors).

a. Please indicate whether you have piano or keyboard skills and to what level. (e.g. piano grade 4 or 'learned for 2 years but did no exams' etc.)

b. How confident are you with reading piano/keyboard music? (e.g. 'Not at all', / 'a little', / 'to about grade 4', / 'fluent' etc. 
11. Can you please make a brief comment about why you chose to do a music degree? Are you doing other study? What can you see yourself doing after you graduate?

12. Please feel free to add any additional comments about either your study experiences or your musical background as it relates to your tertiary music study.

Thank you for agreeing to do this survey. Please attach (scan if emailing) the signed consent form and return both by email to the address above. If you wish to return a hard copy, it can be left at ..................................... addressed to me. (Staple or place in envelope for confidentiality). 


\title{
Appendix II
}

\author{
Talking About Transition \\ An Exploration of the Secondary to Tertiary Transition Process for Music \\ Students in a New Zealand Context
}

Master's Thesis: Researcher - Lynne Wenden

[Email address]

\section{Follow-up Questionnaire}

The following questions are designed to elicit slightly different responses from the initial survey and some of the questions are quite similar so, it might be worthwhile reading them all before you begin to answer. Please be assured that, like the survey, these responses will remain completely confidential.

*I have kept this as a word doc. so that you can manipulate the spaces for answers, as you need them.

Name:

\section{At university:}

- What music class/es have you enjoyed the most and why?

- What music class/es have you enjoyed the least and why?

- What music class/es do you think have been the most valuable and why?

- What music class/es do you think have been the least valuable and why?

- What music class/es were the most difficult and why?

- What do you think are some of the more important aspects/areas of study that the music degree and/or the institution should provide for students - and why?

- What, in your opinion, should the tertiary music institution's main responsibilities be to music students?

- In relation to the class/es that you thought were the least valuable (as above), who do you imagine these classes might be useful to and why?

\section{At secondary school:}

- What aspects of your secondary school study were most useful to you in relation to your preparation for studying at university?

- What aspects of your secondary school study were least useful to you in relation to your preparation for studying at university?

- What did your secondary school study offer you that private instrument/voice tuition did not? 
- Do you have any further comments about studying music at the secondary school level?

\section{General:}

- I am very interested in your opinions about how either the pressures of, for example, performance, NCEA/IB preparation, or any other reason, may have affected your academic performance at university (positively or negatively).

- What age were you when you first thought about the possibility of studying music at university? What were your expectations about tertiary music study and how does the actual experience differ? (Again - positively and negatively).

- Lastly, what does doing/gaining a music degree mean to you?

Thank you for agreeing to do this survey. Please attach (scan if emailing) the signed consent form and return both by email to the address above. If you wish to return a hard copy, it can be left at ...................................... addressed to me. (Staple or place in envelope for confidentiality). 


\title{
Appendix III
}

\author{
Talking About Transition \\ An Exploration of the Secondary to Tertiary Transition Process for Music \\ Students in a New Zealand Context \\ Master's Thesis: Researcher - Lynne Wenden \\ [Email address]
}

\section{(Secondary) Music Student Survey}

This confidential survey asks you about your music study and about the musical journey you have made to date. If you agree, further down the line, to participate in a follow-up interview, I would then ask you to expand on the details you have given here and additionally I may ask about your study experiences. I am interested in obtaining feedback from as diverse a range of students as possible. More importantly, I want to learn from your personal experiences in order to gain a student perspective.

1. Name: Age:

Email:

2. In which city and country do you study music?

(City) (Country)

3. What will be your degree major at university?

*Performance students please be specific about your voice or instrument/s.

4. What is the highest formal theory level you have attained? (e.g. Grade 4 ABRSM / Trinity College/AMEB / or 'no exams but completed theory book 3 'Dulcie Holland series')

5. Please detail where you gained your music skills (both practical and theoretical). (e.g. Taught by private instrumental teacher / through NCEA / Own study at home / or combination of these). Please be specific if you did some study under your private teacher (to what level?) and whether you continued this study at school or elsewhere. 
6a. How many music teachers have you had to date?

(Privately) (In secondary School)

6b. Did you have the same teacher for music theory and practical or did you go to someone specifically for theory tuition?

7. Over how many years / months (approximately) have you studied music theory? Please detail if you have studied theory continuously, perhaps in conjunction with your instrument study or whether you have completed short courses as it became necessary - for example to pass an exam or entry test or similar. Please detail also if you have only studied music theory at secondary school for NCEA or similar.

8. What musical activities at secondary level/teenage years have you pursued beyond private lessons or school instruction? (E.g. Youth orchestra, secondary school jazz and, youth/church choir, YMP, own band or individual performance opportunities). List all if possible.

10. (N.B. Question 10a and 10b are for all students other than piano-performance / harpsichord / organ majors).

a. Please indicate whether you have piano or keyboard skills and to what level. (e.g. piano grade 4 or 'learned for 2 years but did no exams' etc.)

b. How confident are you with reading piano/keyboard music? (e.g. 'Not at all', / 'a little', / 'to about grade 3', / 'fluent' etc.

Thank you for agreeing to do this survey. Please attach (scan if emailing) the signed consent form and return both by email to the address above. If you wish to return a hard copy, it can be left at ....................................... addressed to me. (Staple or place in envelope for confidentiality). 


\title{
Appendix IV
}

VICTORIA UNIVERSITY OF WELLINGTON

Te Whare Wananga o te Upoko o te Ika a Maui

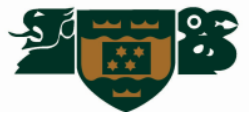

\author{
Talking About Transition \\ An Exploration of the Secondary to Tertiary Transition Process for Music \\ Students in a New Zealand Context
}

Master's Thesis - Lynne Wenden

\section{Participant Information Sheet for Research Project:}

\section{Introduction}

I am a student completing a Master's in Music at Te Kōkī, New Zealand School of Music (NZSM), Wellington. This Master's project examines the circumstances surrounding the diverse learning environments of music students. Secondary school students experience music in formal and informal circumstances not necessarily adhering to traditional pathways of music education. In this, those who wish to pursue a music degree at university face a unique challenge not typically found in other disciplines for example English, science, and mathematics. The challenge for tertiary educators is to recognise and respond to these unique circumstances particularly with regard to the transition process. My project is to further investigate the nature of these pre-tertiary musical environments and to focus on what they may mean for individual students in terms of their preparedness for study at university.

The University requires that ethics approval be obtained for research involving human participants and has granted approval for this project.

What it will involve for you as a participant

As part of the project, I am inviting you, in the first instance (students only), to participate in a survey concerning some aspects of your music study prior to entering university and, where appropriate, I will conduct a follow-up interview which may be in a group setting or individually. Participation is voluntary and should any individual not wish to participate, wish to withdraw, or wish to retract specific information, they may do so without question, without further consequence, and at any time before November 1, 2014.

Responses collected from surveys and interviews will form an integral part of my research project and will be put into a written document. This document will largely report material as aggregated data and as such individuals will not be identifiable. Quotations may be drawn from interview transcripts but these will be attributed only to a pseudonym. The gathered information will not be used for any other purpose without your consent. If you wish, you will receive a copy of the recorded interview (where recorded) and the final thesis will be published and available from the libraries situated at both Victoria and Massey Universities. Survey documents and interview transcripts will be securely stored with restricted access and destroyed within a five-year period. Date 
If you have any further questions about this project, please contact my Master's thesis supervisor or myself:

Dr. Robert Legg

Senior Lecturer - Music Education and Pedagogy

New Zealand School of Music

Robert.legg@,nzsm.ac.nz
Lynne Wenden

Master's Student

New Zealand School of Music

wendenlynn@myvuw.ac.nz 


\section{Appendix V}

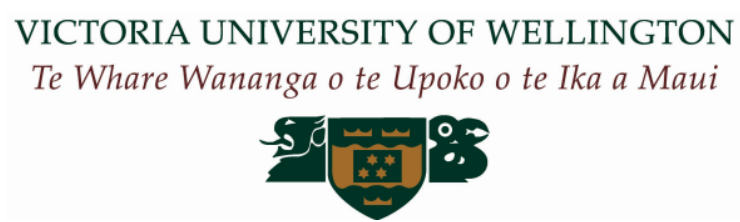

\section{Talking About Transition \\ An Exploration of the Secondary to Tertiary Transition Process for Music \\ Students in a New Zealand Context}

Master's Thesis - Lynne Wenden

\section{Consent to Participate in Research Project:}

I have been given and have understood an explanation of this research project. I have had an opportunity to ask questions and have them answered to my satisfaction. I agree to take part in this research project, and I understand that I may withdraw myself (or any information I have provided) from this project at any point before November 1st 2014.

I understand that any information I provide will be confidential and that the researcher will keep records secure. I understand that my responses from either a survey or interview will be integral to the research project and will be compiled onto a written thesis with pseudonyms used as required. I acknowledge that the gathered information will not be used for any other purpose without my consent, including future publications. I understand that if I request, I will receive a copy of the recorded interview (where recorded) and access to the final thesis will be available through the Massey and Victoria University libraries.

Participant Signature Date

Printed name of Participant

Participant's email

(Should the participant wish to have a transcript of the interview)

If you have any further questions about this project. Please contact the thesis supervisor or myself.

Dr. Robert Legg

Senior Lecturer - Music Education and Pedagogy

New Zealand School of Music

Robert.legg@,nzsm.ac.nz
Lynne Wenden

Master's Researcher

New Zealand School of Music wendenlynn@myvuw.ac.nz 


\section{Appendix VI}

\section{Framework and prompt questions used as a guide for interviews with music educators (Indicative). ${ }^{35}$}

Welcome and thank you for agreeing to meet with me. (A discussion here about the information sheet and consent forms would follow and the documents, if not already in place, would be signed prior to continuing.). My interest is in discovering how music students' diverse learning environments impact on the learning process at university. I am interested particularly in the transition process from secondary to tertiary music study. The purpose of interview is to get your perspective on the transition process and to ask about your thoughts and/or experience with some of the challenges both you and your students face.

'Fishbone' approach to semi-structured interview - Possible stimulus questions:

\section{$\underline{\text { Secondary School }}$}

- What experiences have you had with the transitioning music students through to the tertiary sector?

- What type of initiatives would you consider useful in helping students transition to tertiary music study?

- What sort of collaboration (formal or informal) does the school have with the private sector? (E.g. IRMT)

- What do you personally see as the strengths and weaknesses of NCEA music programmes in terms of preparation for tertiary music study?

- Are certain areas of the curriculum better suited to the transition than others? (E.g. performance, theory, composition?)

- What, if any, barriers to tertiary music study do you see in your role as a music educator?

Other educators (e.g. IRMT members, YMP)

- What experiences have you had with the transitioning music students through to the tertiary sector?

- What, if any, barriers to tertiary music study do you see in your role as a music educator?

- Do you have students who are completing NCEA/IB etc. music study?

- If so, what do you see as your role in this process?

- What communication or collaboration (formal or informal) do you have with the schools that your student/s attend?

- What communication do you have with other educators in your own sector in relation to facilitating possible tertiary study for your students?

- What, if any, initiatives would you see as useful in either the transition process or in collaboration across the different music education sectors?

- What type of initiatives would you consider useful in helping students transition to tertiary music study?

\footnotetext{
${ }^{35}$ Framework used for university ethics approval.
} 